\title{
Transient Side Load Analysis of Out-of-Round Film-Cooled Nozzle Extensions
}

\author{
Ten-See Wang ${ }^{*}$, Jeff Lin ${ }^{\dagger}$, Joe Ruf ${ }^{\ddagger}$, and Mike Guidos ${ }^{\S}$ \\ NASA Marshall Space Flight Center, Huntsville, Alabama, 35812
}

\begin{abstract}
There was interest in understanding the impact of out-of-round nozzle extension on the nozzle side load during transient startup operations. The out-of-round nozzle extension could be the result of asymmetric internal stresses, deformation induced by previous tests, and asymmetric loads induced by hardware attached to the nozzle. The objective of this study was therefore to computationally investigate the effect of out-of-round nozzle extension on the nozzle side loads during an engine startup transient. The rocket engine studied encompasses a regeneratively cooled chamber and nozzle, along with a film cooled nozzle extension. The computational methodology is based on an unstructured-grid, pressure-based computational fluid dynamics formulation, and transient inlet boundary flow properties derived from an engine system simulation. Six three-dimensional cases were performed with the out-of-roundness achieved by three different degrees of ovalization, elongated on lateral $y$ and $z$ axes: one slightly out-of-round, one more out-of-round, and one significantly out-of-round. The results show that the separation line jump was the primary source of the peak side loads. Comparing to the peak side load of the perfectly round nozzle, the peak side loads increased for the slightly and more ovalized nozzle extensions, and either increased or decreased for the two significantly ovalized nozzle extensions. A theory based on the counteraction of the flow destabilizing effect of an exacerbated asymmetrical flow caused by a lower degree of ovalization, and the flow stabilizing effect of a more symmetrical flow, created also by ovalization, is presented to explain the observations obtained in this effort.
\end{abstract}

\footnotetext{
* Aerospace Engineer, ER42, Fluid Dynamics Branch, Propulsion Structure, Thermal, and Fluids Analysis Division, Senior Member AIAA.

${ }^{\dagger}$ Aerospace Engineer, ER42, Fluid Dynamics Branch, Propulsion Structure, Thermal, and Fluids Analysis Division, * Aerospace Engineer, ER42, Fluid Dynamics Branch, Propulsion Structure, Thermal, and Fluids Analysis Division.

$\S$ Aerospace Engineer, ER21, Liquid Engine \& Main Propulsion Systems Branch, Propulsion Systems Design \& Integration Division.
} 


\section{Nomenclature}

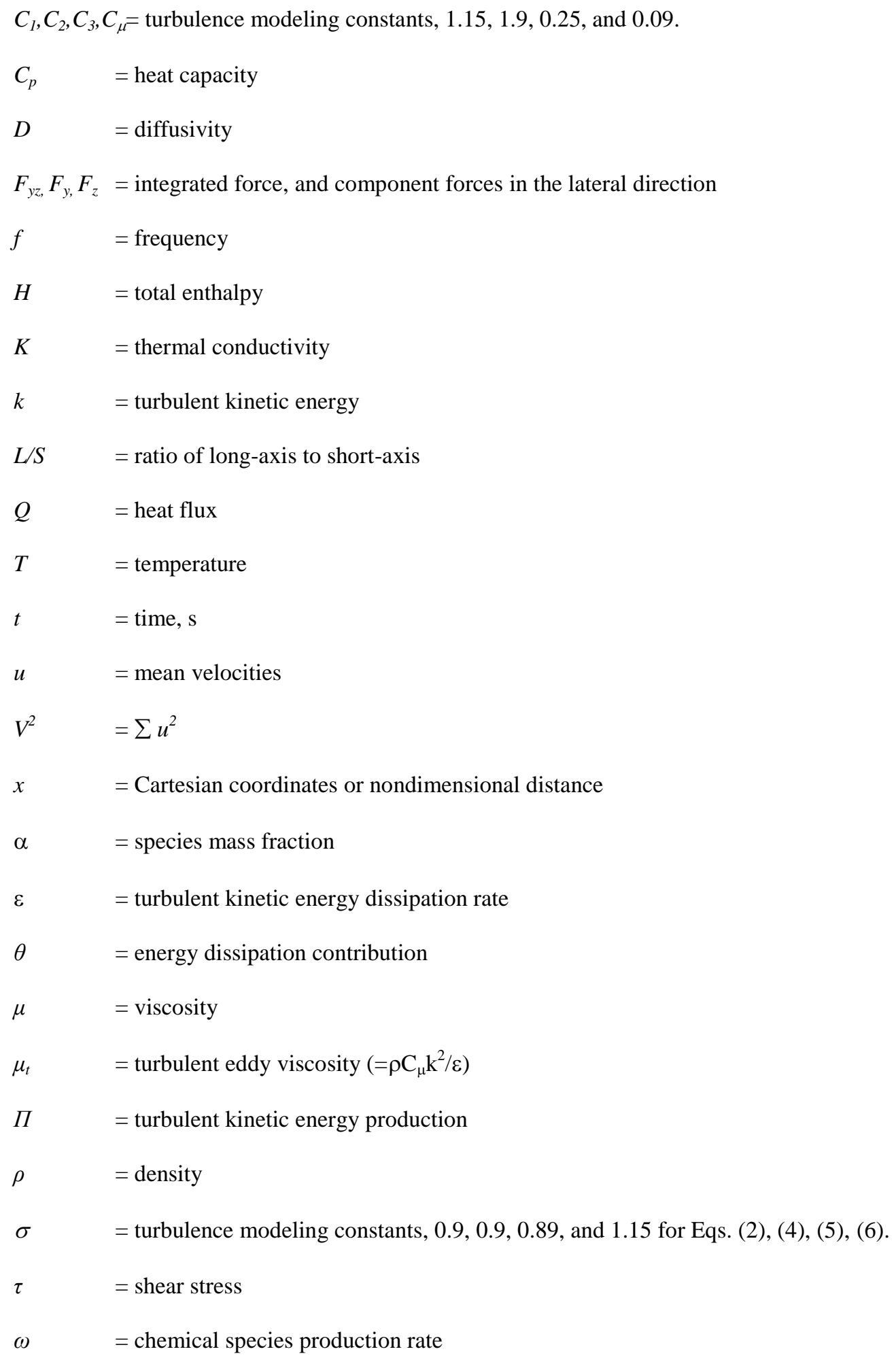

\section{Subscripts}




$$
\begin{array}{ll}
r & =\text { radiation } \\
t & =\text { turbulent flow }
\end{array}
$$

\section{Introduction}

Nozzle lateral forces during startup and shutdown transients, if not properly managed, are known to cause severe structural damages to the engine hardware to almost all liquid rocket engines during their initial development [1-4]. Therefore, transient nozzle side load is considered a high risk item and a critical design issue during any new engine development. For that reason, many research efforts [5-18] have been devoted to understanding the side load physics and their impact on the magnitude of side loads. For regeneratively-cooled engines such as the Space Shuttle Main Engine (SSME), the peak side load generating physics have been identified as the $\lambda$ shock oscillation across the nozzle lip [7]. For film-cooled engines such as the Japanese LE-7A engine and the U.S. J-2X engine, the major side load generating physics have been associated with the jump of the separation line [3, 8]. Other side load physics such as the Free-Shock Separation (FSS)-to-Restricted-Shock Separation (RSS) transition have been mentioned as the critical one for the European Vulcain engine [9].

With respect to the $\mathrm{J}-2 \mathrm{X}$ engine under development, the impact of the side loads caused by the jump of the separation line has been considered. However, liquid rocket engine nozzles, being large, relatively light weight structures, are probably never truly round. The effect of nozzle out-of-roundness, on the transient nozzle side loads is therefore a potential issue and needs to be explored. The causes of nozzle out-of-roundness could be, but are not limited to, asymmetric material internal stresses induced in previous tests, the asymmetric loads induced by other hardware attached to the nozzle, and nozzle wall material deformation, such as creep, induced in previous engine tests.

Our first attempt on this subject, report in Ref. [19], studied the effect of out-of-roundness over the entire thrust chamber (main combustion chamber, nozzle, and nozzle extension), with four different degrees of ovalization: a perfectly round, a slightly ovalized, a more ovalized, and a significantly ovalized. All three ovalized cases were elongated along one of the lateral coordinate, the z-axis only, since it was postulated that the elongation along the other lateral coordinate y-axis is unlikely, due to the attached structure of the turbine exhaust manifold (TEM). The results show that the separation line jump was source of the peak side load for the first three configurations, with the peak side load increasing as the degree of out-of-roundness increased. For the significantly out-of-round case, the 
peak side load was reduced to a level comparable to that of the round nozzle due to a mechanism named splitting of the separation line jump [19].

In this effort, we have shifted our attention from ovalizing the entire thrust chamber to that of the nozzle extension only. Nozzle extension, being structurally thin and not containing cooling tubes, is probably more likely to deform than the other components such as the regeneratively-cooled main combustion chamber and nozzle. Since the elongations in both the lateral $\mathrm{y}$ and $\mathrm{z}$ axes are now likely, six three-dimensional computations were performed with the out-of-roundness achieved by three different degrees of ovalization, and elongated on both $\mathrm{y}$ and $\mathrm{z}$ axes: one slightly out-of-round, one more out-of-round, and one significantly out-of-round. In order to compare results with those of previous study, the maximum deformations of the three different degrees of ovalization are identical to those used in the previous study [19]. The results of these computations are presented and discussed herein.

\section{Computational Methodology}

\section{A. Computational Fluid Dynamics}

The computational fluid dynamics (CFD) methodology is based on a multi-dimensional, finite-volume, viscous, chemically reacting, unstructured grid, and pressure-based formulation. Time-varying transport equations of continuity, species continuity, momentum, total enthalpy, turbulent kinetic energy, and turbulent kinetic energy dissipation were solved using a time-marching sub-iteration scheme and are written as:

$$
\begin{aligned}
& \frac{\partial \rho}{\partial t}+\frac{\partial}{\partial x_{j}}\left(\rho u_{j}\right)=0 \\
& \frac{\partial \rho \alpha_{i}}{\partial t}+\frac{\partial}{\partial x_{j}}\left(\rho u_{j} \alpha_{i}\right)=\frac{\partial}{\partial x_{j}}\left[\left(\rho D+\frac{\mu_{t}}{\sigma_{\alpha}}\right) \frac{\partial \alpha_{i}}{\partial x_{j}}\right]+\omega_{i} \\
& \frac{\partial \rho u_{i}}{\partial t}+\frac{\partial}{\partial x_{j}}\left(\rho u_{j} u_{i}\right)=-\frac{\partial p}{\partial x_{i}}+\frac{\partial \tau_{i j}}{\partial x_{j}} \\
& \frac{\partial \rho H}{\partial t}+\frac{\partial}{\partial x_{j}}\left(\rho u_{j} H\right)=\frac{\partial p}{\partial t}+Q_{r}+\frac{\partial}{\partial x_{j}}\left(\left(\frac{K}{C_{p}}+\frac{\mu_{t}}{\sigma_{H}}\right) \nabla H\right)+\frac{\partial}{\partial x_{j}}\left(\left(\left(\mu+\mu_{t}\right)-\left(\frac{K}{C_{p}}+\frac{\mu_{t}}{\sigma_{H}}\right)\right) \nabla\left(V^{2} / 2\right)\right)+\theta \\
& \frac{\partial \rho k}{\partial t}+\frac{\partial}{\partial x_{j}}\left(\rho u_{j} k\right)=\frac{\partial}{\partial x_{j}}\left[\left(\mu+\frac{\mu_{t}}{\sigma_{k}}\right) \frac{\partial k}{\partial x_{j}}\right]+\rho(\Pi-\varepsilon) \\
& \frac{\partial \rho \varepsilon}{\partial t}+\frac{\partial}{\partial x_{j}}\left(\rho u_{j} \varepsilon\right)=\frac{\partial}{\partial x_{j}}\left[\left(\mu+\frac{\mu_{t}}{\sigma_{\varepsilon}}\right) \frac{\partial \varepsilon}{\partial x_{j}}\right]+\rho \frac{\varepsilon}{k}\left(C_{1} \Pi-C_{2} \varepsilon+C_{3} \Pi^{2} / \varepsilon\right)
\end{aligned}
$$


A predictor and corrector solution algorithm was employed to provide coupling of the governing equations. A second-order central-difference scheme was employed to discretize the diffusion fluxes and source terms. For the convective terms, a second-order upwind total variation diminishing difference scheme was used. To enhance the temporal accuracy, a second-order backward difference scheme was employed to discretize the temporal terms. Point-implicit method was used to solve the chemical species source terms. Sub-iterations within a time step were used for driving the system of second-order time-accurate equations to convergence. Details of the numerical algorithm can be found in Ref's [20-23].

An extended k- $\varepsilon$ turbulence model [24] was used to describe the turbulence. A modified wall function approach was employed to provide wall boundary layer solutions that are less sensitive to the near-wall grid spacing. Consequently, the model has combined the advantages of both the integrated-to-the-wall approach and the conventional law-of-the-wall approach by incorporating a complete velocity profile and a universal temperature profile [25]. A 7-species, 9-reaction detailed mechanism [25] was used to describe the finite-rate, hydrogen/oxygen afterburning combustion kinetics. The seven species are $\mathrm{H}_{2}, \mathrm{O}_{2}, \mathrm{H}_{2} \mathrm{O}, \mathrm{O}, \mathrm{H}, \mathrm{OH}$, and $\mathrm{N}_{2}$. The thermodynamic properties of the individual species are functions of temperature. The multiphysics pertinent to this study have been anchored in earlier efforts, e.g., SSME axial force and wall heat transfer [20], SSME startup side load and dominant shock breathing frequency [7], J-2X startup and shutdown side loads for a nozzlette configuration [8], nozzle film cooling applications [26], and conjugate heat transfer [27].

\section{B. Transient Startup Sequences}

Transient system-level simulation is a vital part of the computational methodology, because it provides the timehistories of the inflow properties entering the nozzle. Simply put, the ramp rates, or histories, of the inlet pressure, fluid temperature and species concentrations play an important role in determining the type of side load physics, magnitude and duration of the side loads during the transient operations. In terms of the type of side load physics, it was demonstrated that a combustion wave occurred during a transient startup of the SSME due to the excess fuel dump [7]; On the other hand, it was also demonstrated that the combustion wave disappeared when the excess fuel dump was replaced with helium purge in the $\mathrm{J}-2 \mathrm{X}$ startup transient [8]. In terms of the magnitude and duration of the side loads, it was demonstrated that the peak side load dropped to about half after the total ramp time decreased from $5 \mathrm{~s}$ to $1 \mathrm{~s}$ [7], for the SSME startup simulation. In addition, the combustion wave captured in the 5-second 
nominal ramp time was eliminated when the ramp time was shortened to $1 \mathrm{~s}$ [7]. In other words, the time-varying inlet flow properties determine the all-important residence time of the side load generating flow inside the nozzle.

The system-level simulation is based on a lumped, control-volume analysis approach to model the rocket engine as a network of components and sub-components. This method of transient system-level modeling has been shown to be effective in simulating the low-frequency, transient physics associated with the operation of previous and existing rocket engines (SSME, RL-10, IPD, etc.) and therefore, is an important tool in the design and planning of sequencing the transient events of rocket engine operation. Figure 1 show the engine system transient model computed inlet fluid pressure and temperature time-histories, for the main combustion chamber (MCC) and the turbine exhaust gas (TEG) flows, during a J-2X startup transient. TEG flow is used as film coolant for the J-2X nozzle extension. The transient reactant species composition (not shown) obtained from system modeling was preprocessed with the Chemical Equilibrium Calculation program [28], assuming the propellants were ignited to reach equilibrium composition immediately downstream of the injector faceplate and turbine exhaust manifold inlet boundary, for the respective MCC and TEG flows. This J-2X engine start transient process involves thermal-fluid physics phenomena and safety-based operating practices that are typical of a conventional LH2/LOX rocket engine based on a gas generator (GG) power cycle with spin-start assistance for the turbomachinery.

During engine start, the GG fuel and oxidizer injectors are both flowed with helium which serves as a purge or buffer flow. This buffer flow reduces the possibility of backflowing of either propellant into the other propellant's manifold during the process of establishing the propellant flows to the GG. After initiation of the GG injector purges, the main fuel valve is the first primary engine valve opened, establishing the initial fuel flow in the main fuel injector and MCC augmented spark igniter (ASI), and thus ensuring a fuel-rich start of the MCC and safely allowing the $\mathrm{J}-2 \mathrm{X}$ fuel turbopump to start increasing in power. The helium spin-start system is then activated, providing the initial break-away momentum to respective pump shafts and causing the increase of pump flow-rates, by injecting a short-duration $(\sim 1.4 \mathrm{sec})$, high-pressure/high-flow of helium gas into the inlet of the fuel turbine, immediately downstream of the GG discharge. The spin-start helium flow back-pressures the GG injector manifolds prior to propellant flowing to the GG and thus delaying the start of the GG. Simultaneous with the initiation of the heliumspin assist system, the main oxidizer valve is opened to allow priming of the downstream oxidizer system with liquid oxygen. Also in this same period, the MCC ASI oxidizer valve is opened, initiating low-flow/low-pressure combustion gas in the MCC ASI chamber and MCC during this early timeframe. In very rapid manner, as the spin- 
start flow diminishes after the helium spin-start valve is closed, the back-pressure to the injectors decays, and the GG injectors are relieved to flow. By precise sequencing of the GG valves in coordination with the helium spinstart valve and the main propellant valves particularly, a fuel-rich lead flow to the GG is established followed shortly after by oxidizer flow to the GG. Once oxidizer and fuel flows are established and within a specified mixture ratio range, the GG pyrotechnic igniter is sequenced to pulse and start combustion of the GG flows. Thus, the processes of the downstream injection of high-pressure helium spin-start flow, GG ignition, the ramp-up of pressure and flow rate throughout the engine, and the priming of the main oxidizer injector with high-density oxygen (supercritical, but typically referenced as "liquid" when describing the injectorpriming process) occur in a nearly simultaneous manner but yet in a very coordinated, chronological sequence that is required for a safe engine start transient. It is during the spin-start system operation, prior to any significant flow through the MCC main injector, that the nozzle side-loads hit a peak magnitude (at $0.80-1.10 \mathrm{sec}$ ).

Further downstream, during the activation of the GG injectors' helium purges and prior

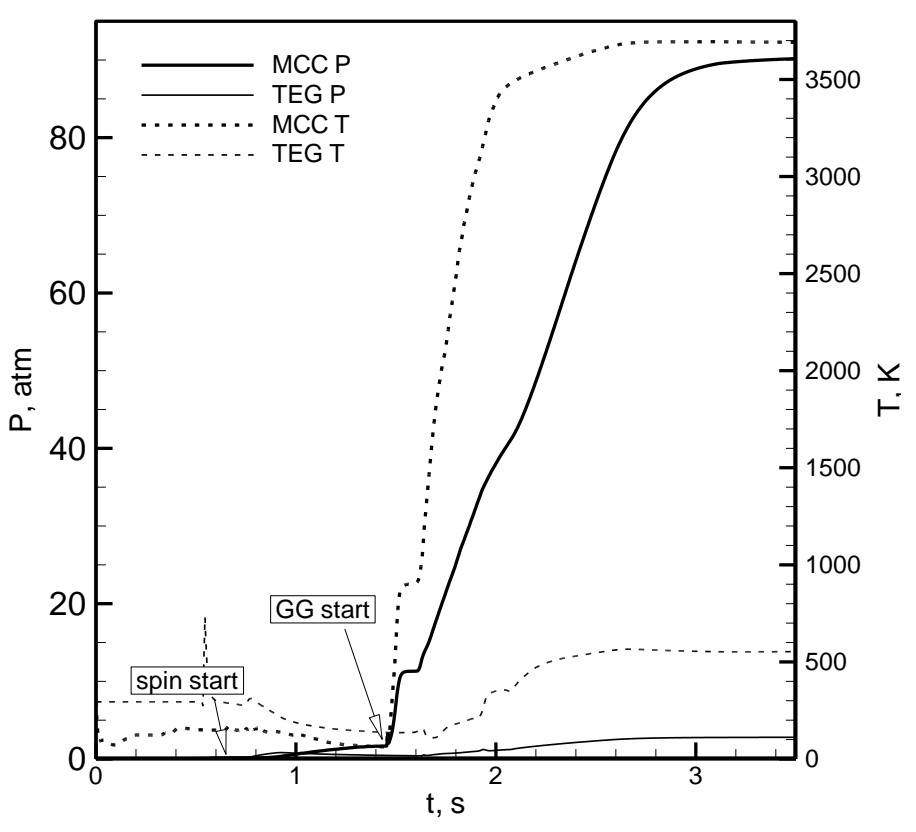
Fig. 1 Computed inlet pressure and temperature histories for the main combustion chamber and turbine exhaust gas flows during the start-up transient.

pressure helium flowfield is established in the nozzle and MCC in the otherwise ambient vacuum environment. This initial flowfield is established via the TEG flowpath, which discharges into the nozzle at the junction of the regen nozzle and nozzle extension. This helium flowfield is further effected as the helium spin-start flow is activated and exhausts into the MCC-nozzle flowfield via the TEG flowpath (after passing through the fuel and oxidizer turbines). The helium in the MCC-nozzle flowfield is later pushed out after the decay of the spin-start flow as the initial fuel and low-flow/low-pressure igniter flows become established to the MCC. However, the discharge of helium spinstart flow from the TEG into the nozzle flow field occurs prior to any significant flow through the main injector, 
thus promoting the possibility of loading the nozzle asymmetrically. As the spin-start helium mass flow decays, the GG fuel and oxidizer valves are opened, causing build-up of the GG hot gas flow rate, thus further accelerating the pumps and powering the buildup of both fuel and oxidizer pressure and flows throughout the engine. This transition from helium spin-start gas to GG-generated hot gas is not instantaneous, and there is a short period of time during which engine system flows and pressures decay.

During the turbine-flow transition period, the oxidizer dome of the main injector primes with liquid oxygen, which is a crucial step in starting the engine safely, as the oxidizer flow entering the MCC then becomes more controllable and predictable, increasing the likelihood for stable MCC combustion as engine power is sharply increased. As the flow through the main oxidizer injector is initiated and then primes to a fully liquid flow, the MCC pressure rises sharply to the first small plateau around the 1.4-1.6 sec timeframe as shown in the transient MCC pressure profile in Fig. 1. The rise in MCC pressure correspondingly causes a decrease in overall fuel system flow and thus decreased fuel to the MCC as well, thus causing the brief stagnation or plateau in MCC pressure. Figure 1 shows that the majority of the increase in MCC pressure and temperature occurs between 1.4 and

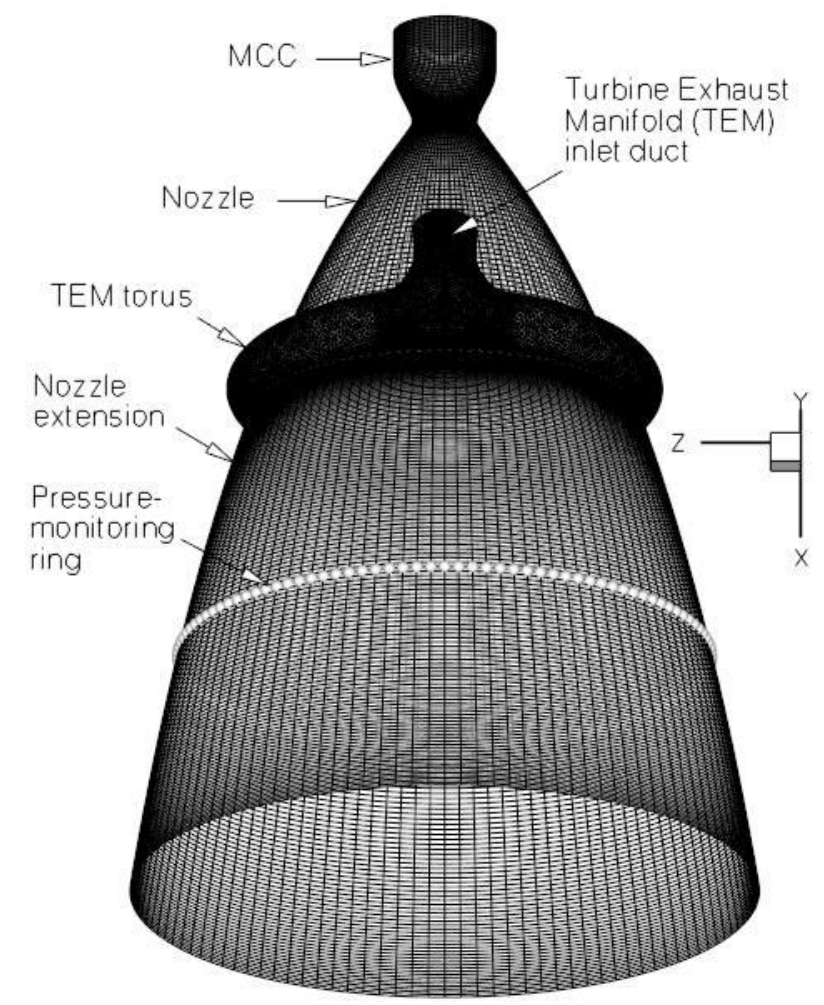

Fig. 2 A grid layout of the round thruster geometry. $3 \mathrm{~s}$.

\section{Computational Grid Generation}

Figure 2 shows a grid layout of the $\mathrm{J}-2 \mathrm{X}$ engine computational model. It includes the MCC, the nozzle, the turbine exhaust manifold (TEM), and the nozzle extension. The TEM consists of an inlet duct and a torus in which the TEG flow splits, flowing around the torus and subsequently into the nozzle extension. The exit of the TEM is a 
narrow annular slot of constant area through which the TEG exhausts onto the nozzle extension inner wall [19, 30]. A separate steady-state mainstage analysis with this TEM configuration indicated it produces a $9 \%$ higher, than uniform, mass flow into the nozzle extension in the region under the TEM inlet duct, for the round nozzle. The pressure monitoring ring shown in Fig. 2 indicates the locations of the monitoring points, where the circumferential pressure distribution was monitored.

The three-dimensional thruster grid, shown in Fig. 2, was generated by rotating an axisymmetric grid first without the TEM. The TEM grid was constructed separately as it is asymmetric to the central axis. The grid was completed by merging these two grids at an interface. The software package GRIDGEN [29] was used to perform the grid generation. The general layout of the outer boundaries and the wall boundaries of the MCC, nozzle, TEM, and nozzle extension are similar to those of a previous J-2X side load study and are, described in detail in Ref. [8]. The rotated grid ensures the grid is symmetrical to the central axis and therefore the computed lateral forces came from the asymmetrical flow physics and not from asymmetrical grid cells.

A grid study procedure was developed for transient nozzle side load computations following the results of a SSME transient nozzle side load study [7], by assuming the grid study can be performed on steady-state axial force computations. This is necessitated by the cost-prohibitive computational requirement for computing a threedimensional, transient, turbulent reacting flow for 3 to $5 \mathrm{~s}$, especially for sea level simulations since both the flow residence time and chemical reaction time are long. In addition, since the peak side force is usually a small percentage of the axial force, it is further assumed that if the grid density is suitable for the steady-state axial force calculations, then it is likely adequate for the transient side force analyses. This procedure was demonstrated adequate as described in the SSME side load study [7] where a total of 1,275,120 grid points and a circumferential division number of 72 were used. The predicted peak side loads and dominant frequency for sea level startup transient agreed very well with those of tests [7], as summarized in Table 1 . The two local peak side loads of 80, and $102 \mathrm{kN}$ were computed from FSS-to-RSS and RSS-to-FSS transitions, respectively. The two dominant frequencies of 122 and $125 \mathrm{~Hz}$ were reduced from pressure and heat flux signals, respectively.

Table 1 A comparison of past CFD results with those of engine tests

\begin{tabular}{|l|c|c|c|c|c|c|}
\hline & Engine & CFD & Engine & Test & Physics & Ref. \\
\hline Local Peak $\mathrm{F}_{\mathrm{yz},}$ & SSME & 212 & SSME & 200 & $\lambda$ shock oscillation over lip & 7 \\
\hline
\end{tabular}




\begin{tabular}{|c|c|c|c|c|l|c|}
\hline $\mathrm{kN}$ & SSME & 80,102 & SSME & 90 & shock transitions & 7 \\
\hline Dominant $f, \mathrm{~Hz}$ & $\mathrm{SSME}$ & 122,125 & SSME & 120 & $\lambda$ shock oscillation over lip & 7 \\
\hline \multirow{2}{*}{$\begin{array}{c}\text { Local Peak } \mathrm{F}_{\mathrm{yz},} \\
\mathrm{kN}\end{array}$} & $\mathrm{J}-2 \mathrm{X}$ & 249 & LE-7A & 259 & separation line jump & 8 \\
\cline { 2 - 7 } & $\mathrm{J}-2 \mathrm{X}$ & 80 & LE-7A & 102 & FSS-to-RSS transition & 8 \\
\hline
\end{tabular}

In our first J-2X side load study [8], three grids with 1,581,306 points, 2,011,912 points, and 2,058,192 points were generated, all with circumferential division number of 72 . The three grids were tested for axial force predictions and that of 2,058,192 points was selected. The computed local peak side loads for startup transient at sea level compared reasonably well with those of a similar engine, also summarized in Table 1. Note that unlike the SSME which is a regeneratively-cooled engine, both the $\mathrm{J}-2 \mathrm{X}$ and LE-7A engines are film-cooled engines. As a result, the peak side load physics switched from $\lambda$ shock oscillation over the nozzle lip for the SSME, to that of separation line jump for the $\mathrm{J}-2 \mathrm{X}$ and LE-7A engines. Subsequently, due to

the availability of more computational resources, a grid size of 4,421,166 points with a circumferential division number of 120 was used in Ref. [19], and a grid size of $20,222,021$ points with a circumferential division number of
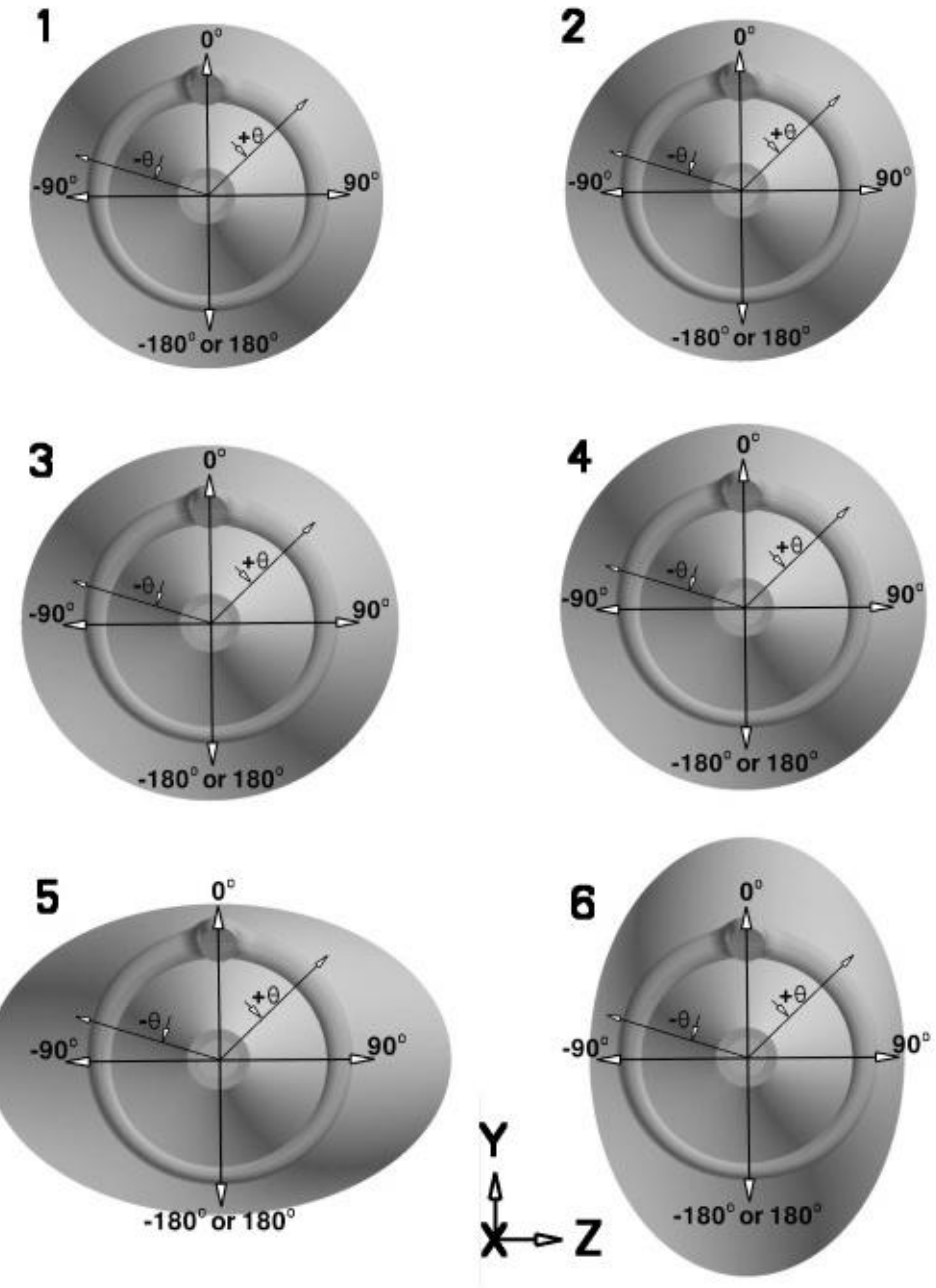

Fig. 3 Cross-sectional view of the six ovalized thrusters. 240 was used in Ref. [30]. In this study, a grid size of 4,421,166 points with a circumferential division number of 
120 was selected for all the cases, due to its better computational efficiency than that of the 20,222,021 points grid, and its better resolution in teepees capturing [30] than that of the 2,058,192 points grid.

In this study, the out-of-roundness was achieved by ovalizing the nozzle extension. Figure 3 shows the crosssectional view of the surface of the six ovalized nozzle extensions. Cases 1, 3, and 5 are the slightly ovalized, more ovalized, and significantly ovalized nozzle extensions that were elongated in the z-direction, respectively; while Cases 2, 4, 6 are those elongated in the y-directions. For convenience of discussion of the results, the $x$ - and y-axes are placed on each of the cross-sectional view of the cases, with the origin placed at the geometrical center. The TEG inlet duct is placed on the y-axis and its azimuthal angle count is zero degree. The angle goes clockwise from zero to 180 degrees, and goes counter-clockwise from zero to -180 degrees for the circumferential pressure profiles. It is noted that although the cross-sectional flow areas of the four nozzles do not have to be the same, it is further assumed that those are the same such that the results are compared on an equal flow area basis. The quantitative outof-roundness follows those of a previous study [19] in which the entire thrust chamber was ovalized, hence the results can be compared on an equal degree of out-of-roundness basis. That is, ratios of the long axis to short axis (L/S) are 1.0086, 1.0346, and 1.4400. The slightly out-of-round case, with a maximum deformation of \pm 0.25 in, is the most likely scenario out of the three. The more out-of-round case, with a maximum deformation of \pm 1.00 in, is also a likely scenario. The significantly out-of-round case, with a maximum deformation of \pm 11.6 in, is a hypothetical case. The purpose of the significantly out-of-round case is to exaggerate the severity of the deformation in order to capture the hidden physics that otherwise may be hidden in the other two cases.

\section{Boundary and Inlet Conditions}

Since $\mathrm{J}-2 \mathrm{X}$ is the upper stage engine of the Ares vehicles, fixed freestream boundary conditions were set corresponding to $100,000 \mathrm{ft}$. Time-varying inlet flow boundary conditions were used at the MCC and TEG inlets. These inlet flow properties (obtained from the system level simulations) were the time varying total pressure, temperature and reactant compositions. For engine startup computations, the thermal wall boundary condition was

initially adiabatic. When the startup transient simulation reached $1.4 \mathrm{~s}$, the point where the MCC pressure started to ramp up, wall temperature profiles obtained from a separate steady-state calculations were imposed onto the MCC and nozzle wall. The nozzle extension and TEM walls remain adiabatic (discussed in [7, 8]). 


\section{Results and Discussion}

The computations were performed on a cluster machine using 10 to 15 processors. For these transient computations at 100,000 ft, because the reaction rates of combustion at such low back pressures are low (compared to the rates at sea level), a global time step of $10 \mu \mathrm{s}$ was used throughout the computations. These global time steps used correspond to CFL numbers ranging approximately from 0.1 to unity. The run matrix of the six cases is shown in Table 2. The perfectly round case has a unity L/S ratio and zero deformation. The result of the nominal case will be discussed first, followed by those of the six out-of-round nozzle extension cases.

Table 2 Run matrix

\begin{tabular}{|c|c|c|c|c|c|}
\hline Case & Description & L/S ratio & Deformation, in & Long axis & Ref. \\
\hline Nominal & perfectly round & 1.0000 & \pm 0.00 & - & 19,30 \\
\hline 1 & slightly out-of-round & 1.0086 & \pm 0.25 & $\mathrm{z}$ & this work \\
\hline 2 & slightly out-of-round & 1.0086 & \pm 0.25 & $\mathrm{y}$ & this work \\
\hline 3 & more out-of-round & 1.0346 & \pm 1.00 & $\mathrm{z}$ & this work \\
\hline 4 & more out-of-round & 1.0346 & \pm 1.00 & $\mathrm{y}$ & this work \\
\hline 5 & significantly out-of-round & 1.4400 & \pm 11.6 & $\mathrm{z}$ & this work \\
\hline 6 & significantly out-of-round & 1.4400 & \pm 11.6 & $\mathrm{y}$ & this work \\
\hline
\end{tabular}

\section{A. The Nominal Case}

The result of the perfectly round case is discussed in here first to establish a baseline that leads to the presentation of the out-of-round cases, albeit at a different angle from that of Ref. [19]. That is, instead of showing computed total side load, $F_{y z}$ versus time, computed histories of lateral forces $F_{y}$ and $F_{z}$ are shown in Fig. 4 , with the timeline of the major side load physics indicated on the right-hand-side of the figure. As indicated by the major physics timeline shown in Fig. 4, core jet flow came out as a subsonic core jet after the start command. At $0.4 \mathrm{~s}$ into the transient, a Mach disk developed and the core jet transformed into a Mach disk flow. Since this initial Mach disk 
flow is separated from the throat down, the combination of this flow separation pattern and the associated shock structure of the Mach disk flow is named the free-shock separation after Nave and Coffey [1], as the supersonic jet stemming from the triple point is flowing freely away from the wall. As this Mach disk flow advances downstream, the size of the Mach disk grows as the nozzle flowing area increases. At about $0.55 \mathrm{~s}$ into the engine start, the initial TEG flow begins to emerge from the TEG exit ring into the nozzle extension. Since the TEG inlet duct is located at zero degree, the initial TEG flow is asymmetric. The TEG flow distribution imbalance inevitably draws the supersonic jet towards the TEM inlet duct side of the nozzle at around $0.82 \mathrm{~s}$,

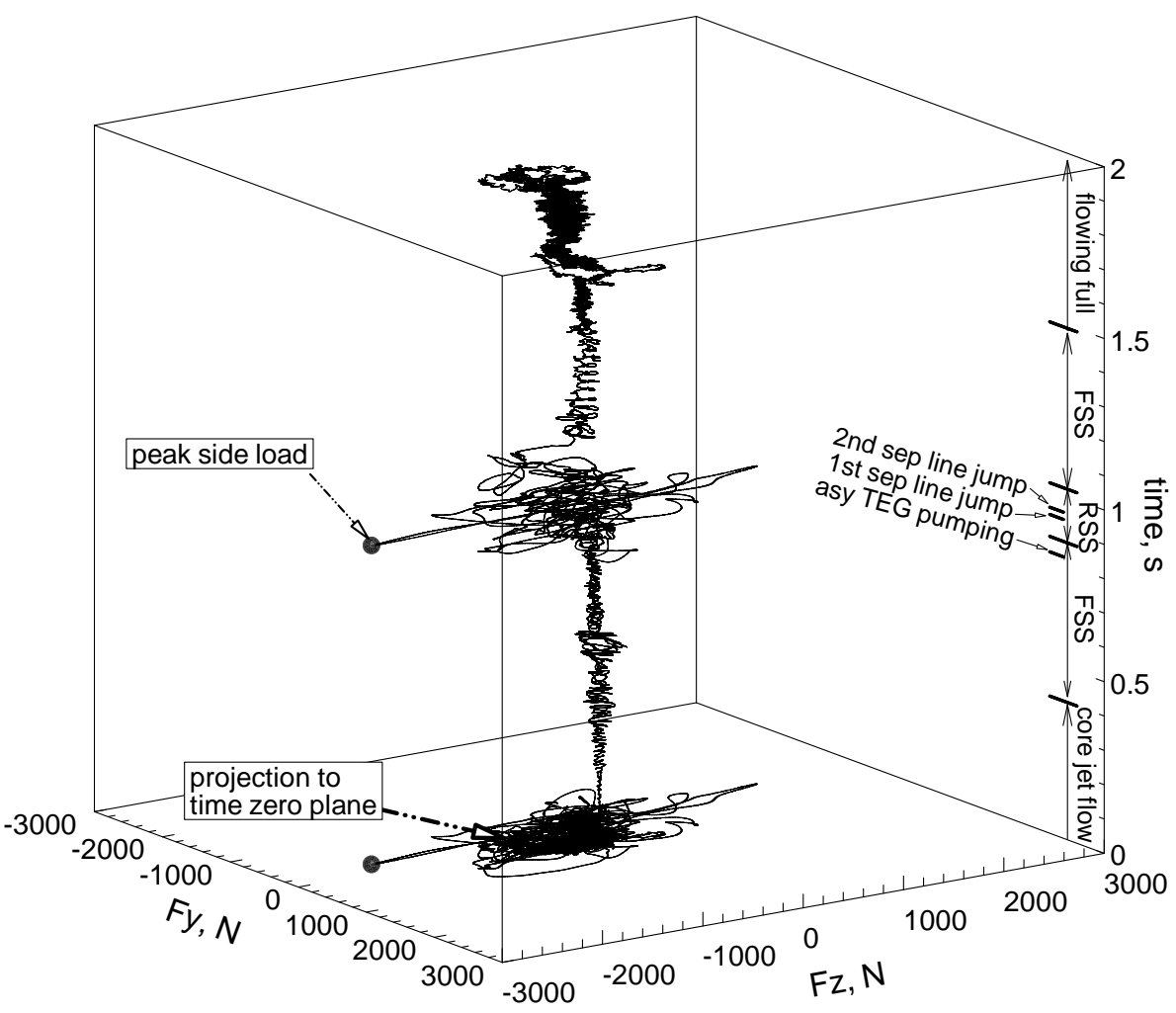

forming an asymmetric Mach disk flow with a Fig. 4 Computed side load history during startup for the perfectly round case. slanted separation line. This phenomenon is unique to this TEM configuration during startup and is named as the "asymmetric TEG pumping" in Ref. [19]. As a result, this phenomenon helps the asymmetric FSS Mach disk flow transiting into an asymmetric RSS Mach disk flow, generating the first local peak side load at about 0.865 s. In a RSS flow pattern, first observed and reported during J-2 and J-2S tests, the entire supersonic jet is attached or restricted to the nozzle wall [1]. Unlike the FSS flow pattern, which has only one separation line, the RSS flow pattern has at least one separation line and one reattachment line, and sometimes multiple separation lines and reattachment lines. 
At this time, the rear shock stem is fast approaching the TEG exit ring that composed of a small "base", or a back-step formation between the nozzle contour and the TEG exit ring. As one would expect, when the rear shock stem jumps over the base and meets with the flowing TEG flow, a significant disturbance is imposed onto the Mach disk flow. By $0.929 \mathrm{~s}$ into the startup transient, the rear shock stem, or the separation line, had jumped over the TEG exit ring and generated the peak side load of $2114 \mathrm{~N}$. This separation line jump phenomenon was first reported by Watanabe [3] as a "separation point jump" during LE-7A engine tests, while Wang [8] captured it later computationally in a J-2X transient startup study. Since the separation line jump always produces a peak side load, it is considered as the critical side load physics for round, film cooled nozzles. Tomita, et al noted that higher base step-height exaggerates the effect of separation line jump [31]. The separation line then moves backup over the TEG exit, then coming down again for a second separation line jump at around $0.945 \mathrm{~s}$, with a lower associated side load and hence is often ignored. At $1.01 \mathrm{~s}$, the RSS Mach disk flow transitioned back to a FSS Mach disk flow, generating another lower local peak side load. This FSS Mach disk flow oscillated several more times in the nozzle and eventually left the nozzle at around $1.49 \mathrm{~s}$.

While the biggest radius in Fig. 4 indicating when the critical separation line jump occurs, Figure 4 also provides a physical aspect that does not show up in the conventional total side load history plot. That is, it shows the lateral forces are moving tangentially as the flow moves downstream, or as time accumulates. The tangential motion of the lateral forces is only temporarily disrupted by major side load physics such as the separation line jump. After the disruption, the tangential motion recovers and resumes its movement along the axial direction. This tangential motion of the lateral forces was captured and reported in the SSME startup at sea level study [7], and captured again in this study even at $100,000 \mathrm{ft}$ with a shorter flow residence time. The projection of the time-varying locus of the lateral forces onto the plane of time zero shown in Fig. 4 gives a conventional, two-dimensional polar plot. 
Before entering the discussion of the out-of-round cases, a theory that was gradually developed in this study and a rationale of using circumferential distribution to demonstrate that theory is best presented first. That is, any deformation of the thruster geometry creates a disturbance that makes the flow unstable, or more asymmetrical; On the other hand, any deformation also produces a flow directionality that guides the flow in certain favorable direction and stabilizes the flow. The balance of these two counter-acting mechanisms decides whether the flow becomes more stable, or more unstable, which also depends on the degree of out-of-roundness and the design of the nozzle. One way to tell which way the flow might be going is through the interrogation of circumferential pressure profiles. As shown previously in Fig. 2, a pressure monitoring ring is strategically placed between the TEM torus and the nozzle extension exit plane, such that the

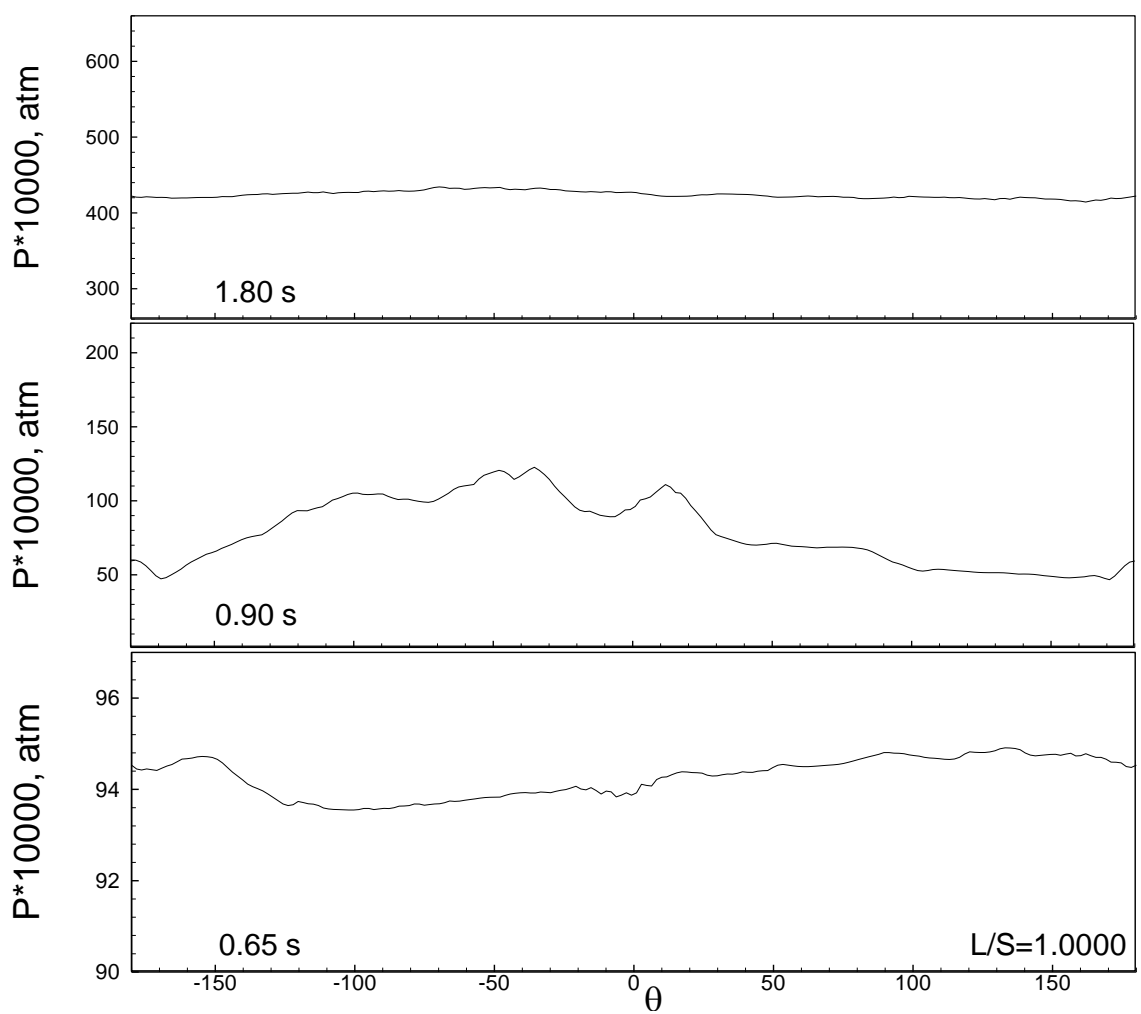

Fig. 5 Computed circumferential pressure profiles at different time slices during startup for the perfectly round nozzle extension.

pressure disturbance caused by the geometrical deformation and the pressure stabilization evolved from the flow directionality can be sensed. However, it is surmised that when the major side load physics occur, the combined pressure disturbances from the side load physics and the geometrical deformation would overshadow that of the pressure stabilization owing to the flow directionality. We therefore present the computed circumferential pressure distribution at selected time slices that less affected by the major side load events. Three discrete time slices were selected for this purpose: $0.65 \mathrm{~s}, 0.90 \mathrm{~s}$, and $1.80 \mathrm{~s}$, as shown in Fig. 5 for the circumferential pressure profiles of the nominal case. By examining the computed results, $0.65 \mathrm{~s}$ is a time when the TEG flow fully covers the monitoring 
ring, yet without any influence from the Mach disk flow, hence it is a good time when the effect of deformation on TEG flow can be felt. The time slice of $0.90 \mathrm{~s}$ is a snapshot after the shock transition and before the separation line jump, hence it is probably a less disturbed time before the disturbance of the critical side load physics arrive. The time slice of $1.80 \mathrm{~s}$ is about $0.3 \mathrm{~s}$ after the nozzle extension flowing full. It is a time that all major side load physics have disappeared, and the pressure profile should reflect nothing but the effect of flow directionality, if there is any. However, the pressure variations at $0.65 \mathrm{~s}$ and $0.90 \mathrm{~s}$ in Fig. 5 are just reflections of the effect of lateral forces

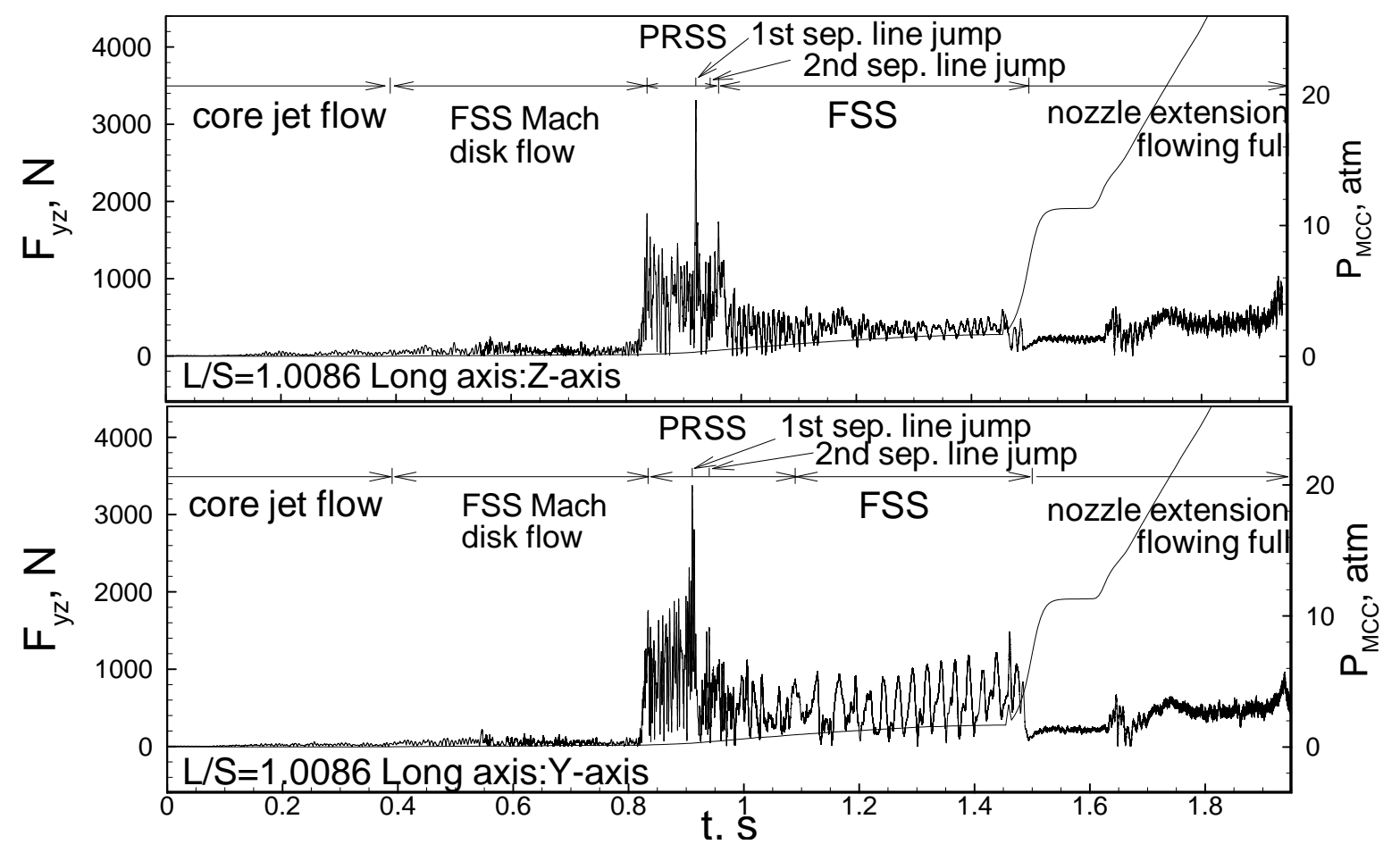

Fig. 6 Computed side load history during startup for the slightly out-of-round Cases 1 and 2.

moving tangentially and showing no sign of flow directionality. The pressure profile at $1.80 \mathrm{~s}$ in Fig. 5 is largely uniform and showing no signs of flow directionality either. These results are not surprising since there is no flow directionality in a round thruster.

\section{B. Slightly Out-of-round Nozzle Extension Cases}

Figure 6 shows the computed side load histories and the timelines of the major side load physics for the slightly out-of-round nozzle extension cases. As shown in Table 2 and Fig. 3, Case 1 is elongated in the z-direction, while Case 2 is elongated in the y-direction. As a reminder, these cases represent nozzle extensions permanently deformed 
due to the internal stresses. The elongation happened in both $\mathrm{z}$ - and y-directions since the nozzle extension is thin and the material is flexible. Also plotted in Fig. 6 is the main combustion chamber inlet pressure history. It can be seen that the pressure ramps up very slowly from about $0.8 \mathrm{~s}$, or spin start, then it ramps up rapidly after about 1,47 s, or GG start. Since the nozzle extension flows full after about $1.5 \mathrm{~s}$, it can be said that all the major side load physics occur during the spin start period. This is because the Mach disk flow is practically evacuated out of the thruster by the low ambient pressure at $100,000 \mathrm{ft}$, with the ambient serves as a vacuum pump. Since the out-ofroundness of the nozzle extension is slight, most of the major side load physics that occurred in the nominal case also happened in here, although notably missing is the asymmetric TEG pumping. It is speculated that although the out-of-roundness is small, the added small directionality is enough to stabilize both the TEG flow and the core flow temporarily, thus suppressed the early asymmetric TEG pumping action. Once that short time span is passed, and at about $0.83 \mathrm{~s}$ into the transient, the Mach disk is big enough such that the supersonic jet feels the slight asymmetry of the nozzle extension and becomes more asymmetric (than that of the perfectly round nozzle extension), resulting in a more asymmetric FSS-to-Partial RSS (PRSS) transition, and even more unstable separation line jump. The results are increased peak side loads of more than $57 \%$ and $60 \%$, respectively for Case 1 and Case 2, comparing to that of the perfectly round case. Also, due to the slight out-of-roundness of the nozzle extension, the supersonic jet had a hard time attach to the wall for the full RSS flow pattern. That resulted in FSS-to-PRSS and PRSS-to-FSS transitions. PRSS is a Mach disk flow separation pattern between that of a FSS and a RSS Mach disk flow separation patterns. That is, the supersonic jet is only partially attached to the nozzle extension wall. PRSS was first captured computationally in the unsteady simulations of LE-7, LE-7A, and CTP50-R5-L nozzles by Wonezawa, et al [32] and later captured by Wang [7] in the transient startup computation of an SSME nozzle as well. 
Figure 7 shows the computed circumferential pressure distributions at selected time slices during startup transient for the slightly out-of-round nozzle extension. At $0.65 \mathrm{~s}$, when the pressure profile could show effect of the slight flow directionality on the TEG flow, the slight elongation in the z-direction case gives a minimum pressure near 90 degree, while the slight elongation in the y-axis gives a minimum pressure near -90 degree. If we reason that higher local mass flow results in lower local pressure, then one can see that at $0.65 \mathrm{~s}$, more film coolant flow should show up at near 90 degree and -90 degree locations for the slight elongation in the z-direction case, while more film coolant flows should prefer near the 0 degree and 180 degree locales for the slight elongation in the $\mathrm{y}$-direction case. However, the local pressure minimums only confirmed one quarter of the confirmation. Hence, the local flow directionality due to the slightly out-of-roundness was enough to eliminate the TEG flow pumping, but not enough to overcome the instability caused by the slight deformation. At 0.90 s, which

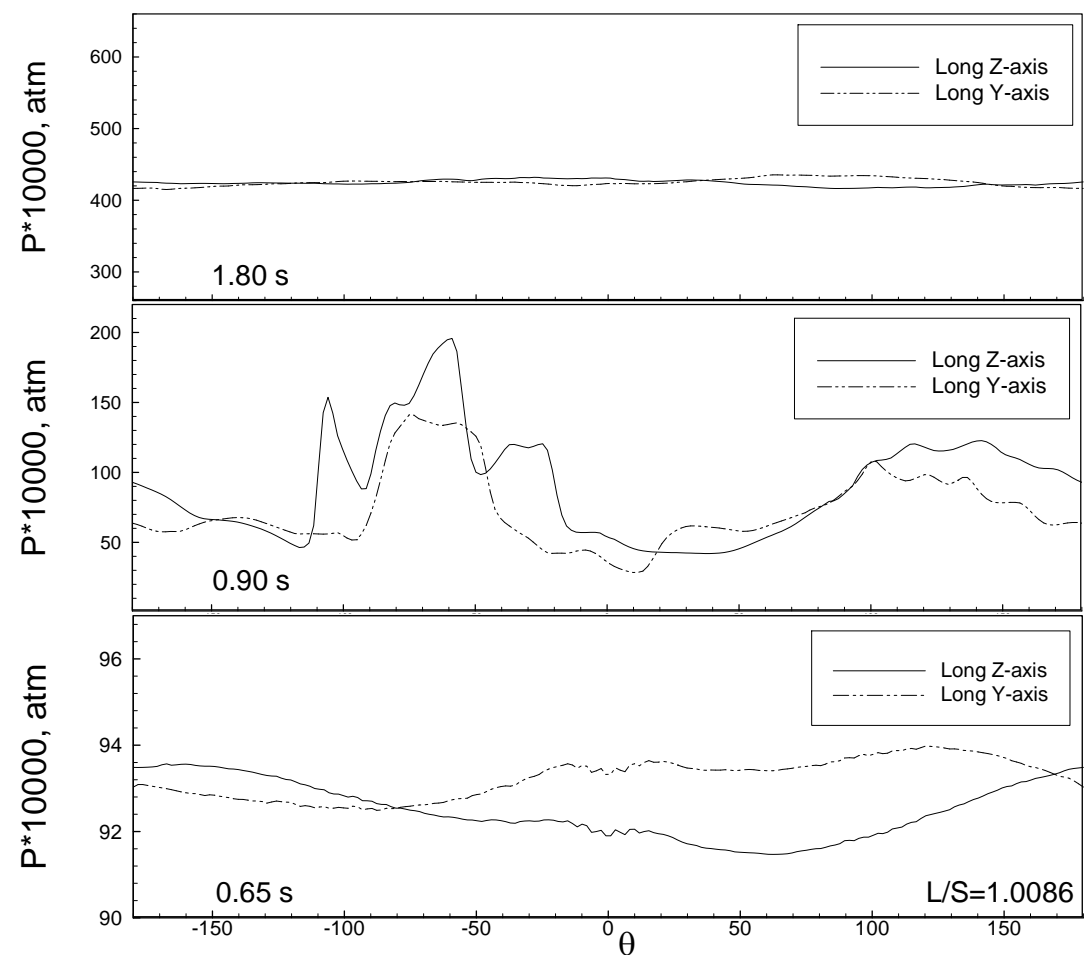

Fig. 7 Computed circumferential pressure profiles at different time slices during startup for the slightly ovalized nozzle extension.

is just before the separation line jump occurring, the pressure profiles for both cases appear in phase and have local pressure minimum at about 40 and -120 degree, and 10 and -90 , for the long z-axis and long y-axis cases, respectively. Hence, there is no sign of flow directionality at $0.90 \mathrm{~s}$. At $1.80 \mathrm{~s}$, the pressure profiles for both cases appear to be near uniform. So, there is no sign of flow directionality at $1.80 \mathrm{~s}$, either.

\section{More Out-of-round Nozzle Extension Cases}


The more out-of-round nozzle extension cases have a slightly larger L/S ratio of 1.0346 or a \pm 1 in. physical deformation. Such an out-of-roundness is also a likely scenario when there are internal stresses built up through many hot-fire tests. Figure 8 shows a comparison of the computed side load histories during startup transient for the more out-of-round cases, ovalized and elongated along z- and y-directions, or Case 3 and Case 4. The major side load physics depicted in Fig. 8, are similar to those described in Fig. 6. And again, we have PRSS occurring after the shock transition due to the out-of-roundness of the nozzle extension. One difference in major side load physics worth noting is the long $\mathrm{z}$-axis case has two separation line jumps, whereas the long y-axis case has only one separation line jump. It is speculated that since the TEG inlet duct is located at 0 degree, or along the y-axis, and intuitively there should be more film coolant flowing under the TEG inlet duct side in the beginning of the TEG

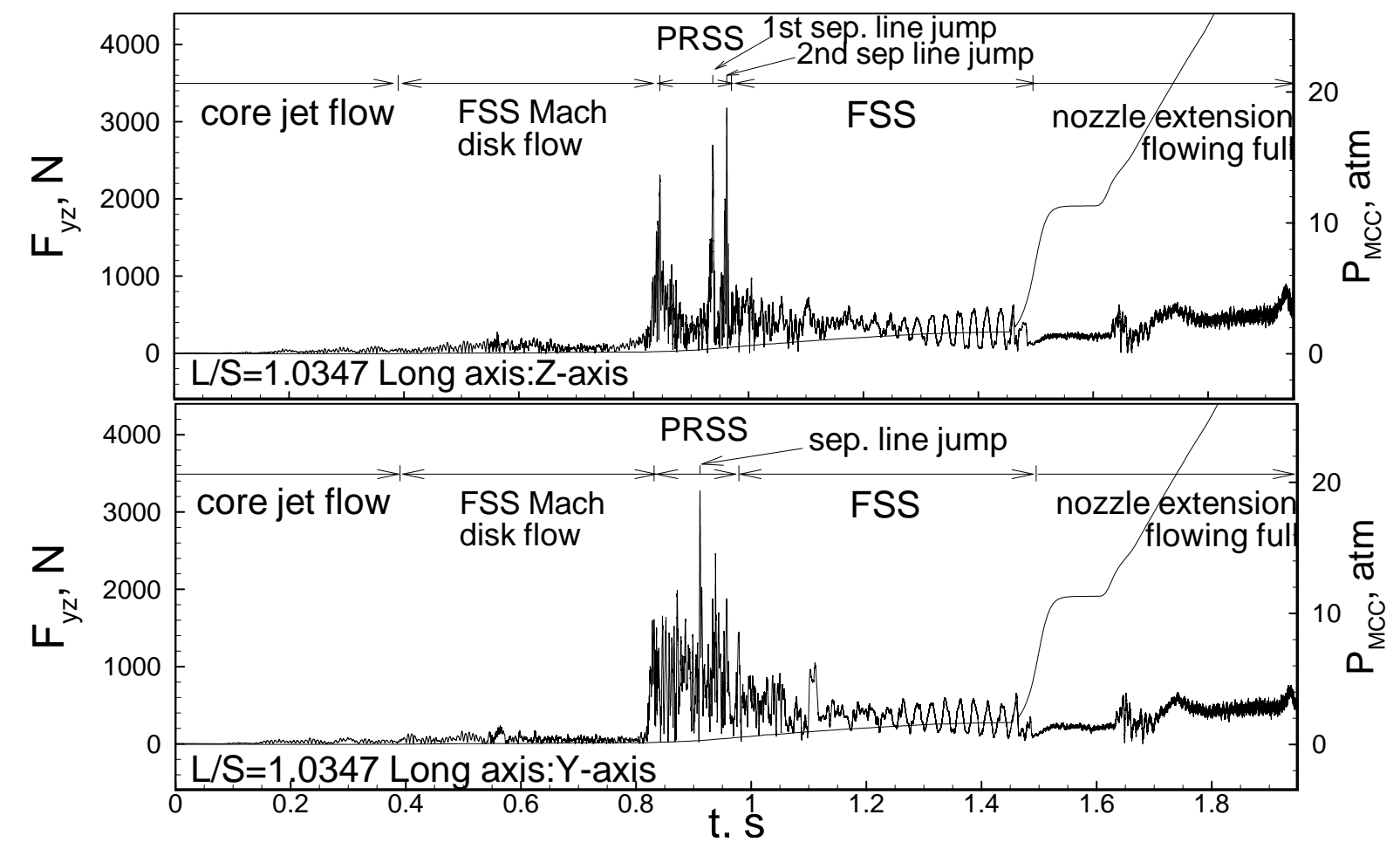

Fig. 8 Computed side load history during startup for the more out-of-round Cases 3 and 4.

emergence, because the TEG inlet duct is closer to the wall for the long axis case than that of the long y-axis case.. The long $y$-axis case is therefore more stable than the long z-axis case, hence it had only one separation line jump.

Figure 9 shows the comparison of the computed circumferential pressure distributions for Case 3 and Case 4 . At $0.65 \mathrm{~s}$ into the transient, this time the peak film coolant flow appears to be near 0 degree location for the long $\mathrm{z}$-axis case, while that of the long $\mathrm{y}$-axis case appears to be near the -90 degree location, still no evidence of flow 
directionality. At $0.91 \mathrm{~s}$ into the startup transient, just before the separation line jump, the pressure profiles for the two cases appear to be out-of-phase. And, the minimum pressure, or the high flow, occurred at 180 degree location for the long z-axis case, while that of the long y-axis case happened near the 0 degree location. Again, there is no strong sign of flow directionality for the two cases at $0.91 \mathrm{~s}$. At $1.80 \mathrm{~s}$, however, after the nozzle extension flowing full, the effect of higher degree of out-of-roundness is starting to show. That is, there are two local pressure minimums occurring for the long z-axis case, at near 90 degrees and -90 degrees, respectively. In the mean time, there are two local pressure minimums occurring for the long y-axis case as well, at near 0 degrees and 180 degrees. The flow directionality definitely shows for the 1.80 s pressure profiles, since the effect of transient flow phenomena are long gone. I can also be said that the effect of flow directionality of the more out-ofround cases is slightly bigger than that of the slightly out ofround cases during the separation line jump, just it was overshadowed slightly by the effect of deformation. Hence, the peak slide loads for Case 3 and Case 4 only increased by $50 \%$ and $55 \%$, respectively; slightly less than those of $57 \%$ and $60 \%$ for Case 1 and Case2, respectively.

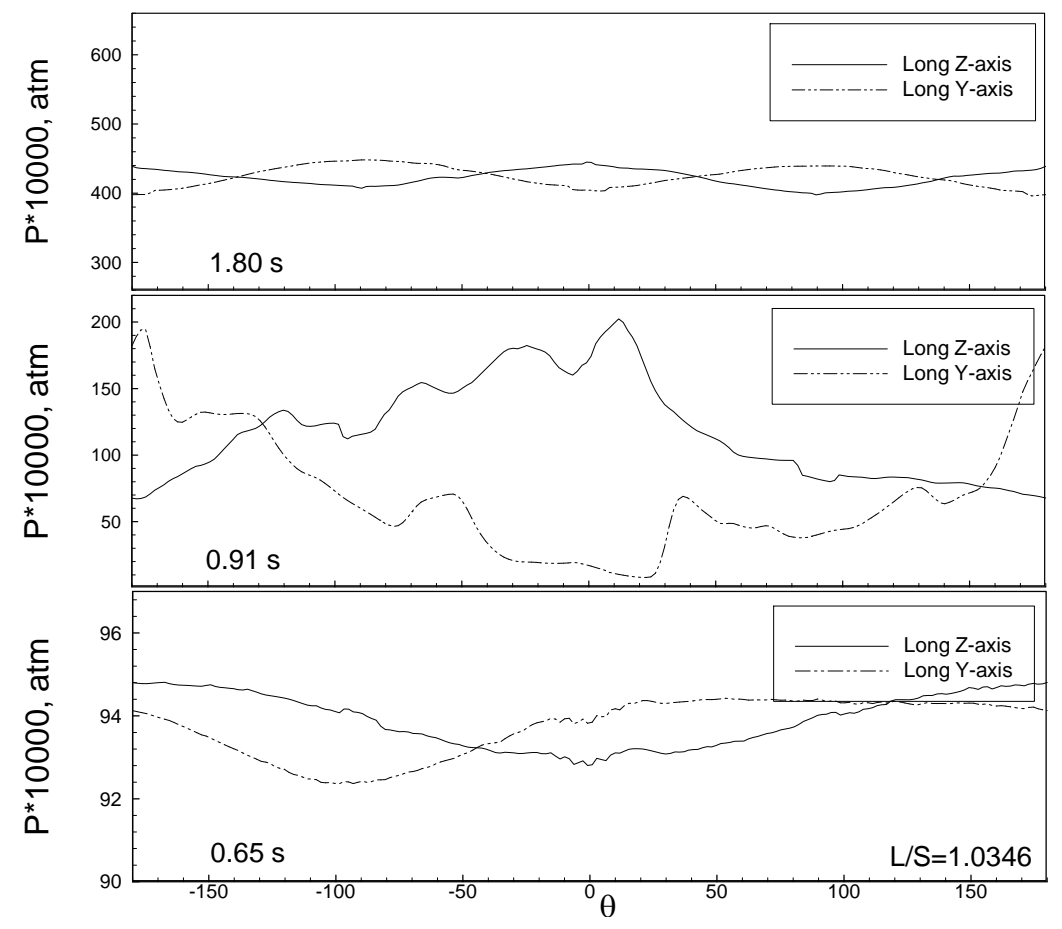

Fig. 9 Computed circumferential pressure profiles at different time slices during startup for the more ovalized nozzle extension.

\section{Significantly Out-of-round Nozzle Extension Cases}

The results of the last two cases, or Case 5 and Case 6, are the hypothetical, significantly out-of-round nozzle extension cases. With a long-axis-to-short-axis ratio of 1.4400 , and a maximum physical deformation of \pm 11.6 in at the nozzle extension exit plane, it is anticipated that the flow stability improves with the increased flow 
directionality. As a result, the computed peak side loads should be lower than those of the four afore-mentioned cases. Figure 10 shows the computed side load histories during startup transient for the significantly out-of-round cases. Indeed, the computed peak side loads are now $+28 \%$ and $-18 \%$ from those of the nominal cases, and much lower than those of the more out-of-round cases. In addition, due to the significant ovalization of the nozzle extensions, instead of the having the major side load physics consisting FSS-to-PRSS transition, separation line jump, and PRSS-to-FSS transition; we now have major side load events comprising FSS-to-PRSS transition, separation line jump, PRSS-to-FSS transition, FSS-to-PRSS transition, and PRSS-to-FSS transition. That is, two more shock transitions before the nozzle extension is flowing full. Furthermore, in the long z-axis case, we have three separation line jumps, while there is only one separation line jump for the long y-axis case. Again, this is because the TEG inlet duct is closer to wall in the long z-axis case, while the TEG inlet duct is farther away from the wall. As a result, Case 6 is more stable than Case 5. For the same reason, the peak side load of Case 6 is significantly less than that of Case 5 .

The reason of the peak side load of Case 6 is lower than that of Case 5 can also be explained by the computed circumferential pressure distributions at selected time slices of $0.65 \mathrm{~s}, 0.92 \mathrm{~s}$, and $1.80 \mathrm{~s}$, as show in Fig. 11. At 0.65 $\mathrm{s}$, when there is no interaction between the TEG flow and the Mach disk flow, the pressure profiles are solely coming from the contribution of the TEG flow. It can be seen that there are two local pressure minimums located at 90 degree and -90 degree for the long z-axis case, and two local pressure minimums located at 0 degree and 180 degree for the long-y-axis case. This exhibition of clear flow directionality can be visualized from the crosssectional view of Case 5 and Case 6 in Fig. 3, where the least flow resistances to the film coolant for the long z-axis case are the 90 degree and -90 degree locations. Similarly, the least flow resistances to the TEG for the long y-axis case are the 0 degree and 180 degree locations. Recall that similar phenomenon was not revealed until at $1.80 \mathrm{~s}$ for the more out-of-round cases in Fig. 9. In the significantly out-of-round cases, this phenomenon, or strong flow directionality due to significant ovalization of the nozzle extension, just happened much earlier, at $0.65 \mathrm{~s}$. The effect of flow directionality occurs earlier as the degree of out-of-roundness increases. 
At $0.92 \mathrm{~s}$ into the startup transient, just before the occurrence of the peak side load physics - the jump of the separation line, one can see that the long y-axis case has two local pressure minimums, located at approximately 0 degree and 180 degree, showing strong influence from the flow directionality; while the long z-axis case has only one local pressure minimum, located at around 120 to 180 degrees, showing no sign of flow directionality. That means that at this time, the flow of the long $y$-axis case is more symmetric and more stable, than that of the long $\mathrm{z}$ axis case, assisted by more flow directionality, just before the separation line jump. As a result, the peak side load

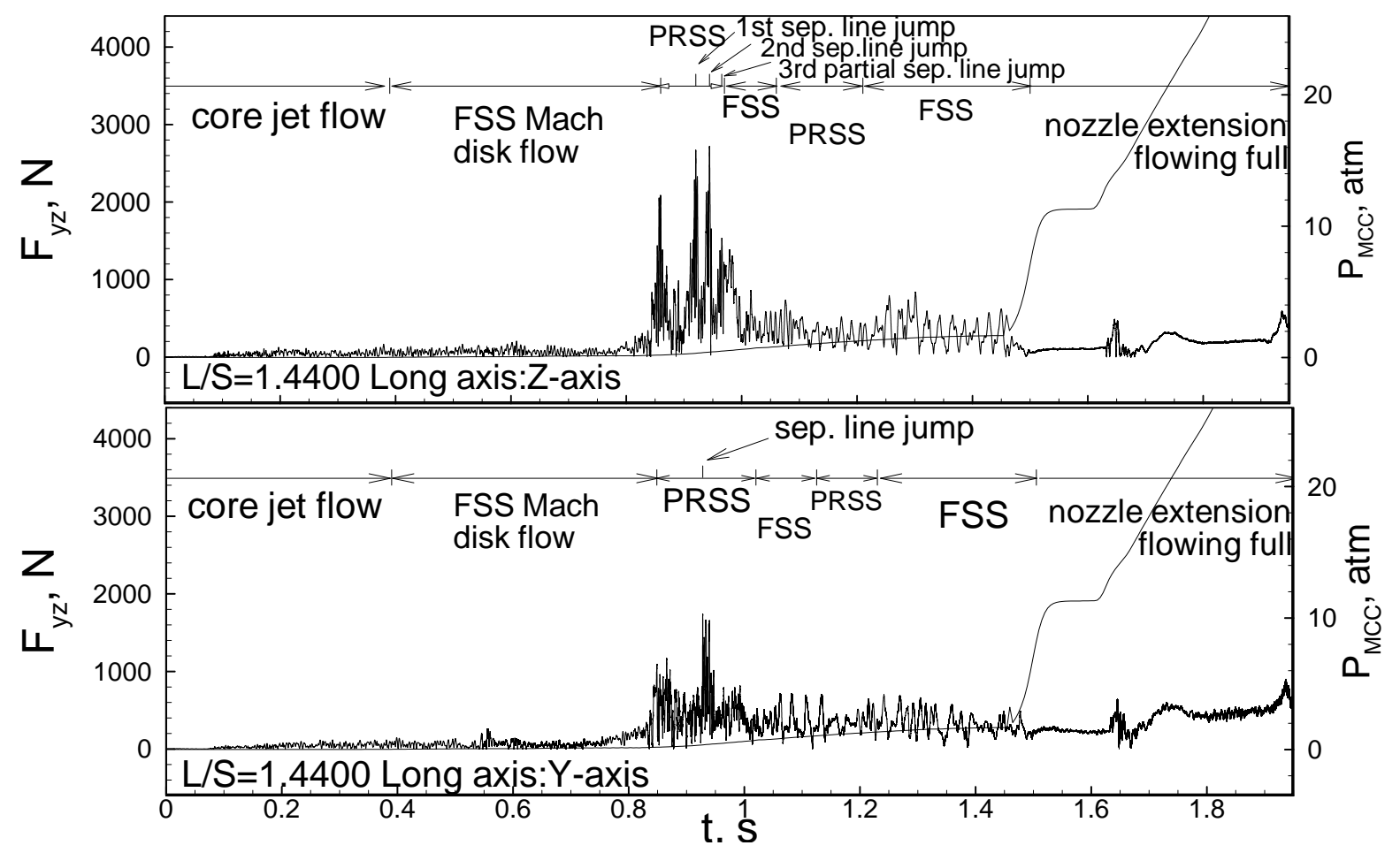

Fig. 10 Computed side load history during startup for the significantly out-of-round cases $(\mathrm{L} / \mathrm{S}=1.4400)$.

due to separation line jump of the long y-axis is much lower than that of the long z-axis case; in fact, $18 \%$ lower than that of the nominal case. Finally, at $1.80 \mathrm{~s}$ into the startup transient, when the nozzle extension is flowing full, the effect of flow directionality manifested itself strongly. The flow at the long $\mathrm{Z}$-axis case clearly favors the 90 degree and -90 degree directions, while that of the long y-axis case clearly prefers the 0 degree and 180 degree directions. The flows at the two cases are now symmetric. 
The major flow physics of case 6 are now presented as Mach number contours at selected time slices, as shown in Fig. 12. For each time slice, two pictures are shown. The picture on the left-hand-side is the Mach number contours on the xy-plane, while that on the righthand-side is the Mach number contours on the $\mathrm{xz}-$ plane. The xy-plane views the long-axis side, or wider dimension of the ovalized nozzle, and the xz-plane views the short-axis side, or narrower dimension of the ovalized nozzle. During the initial startup transient, the FSS Mach disk flow starts at about $0.39 \mathrm{~s}$, while the TEG emerges at about 0.55

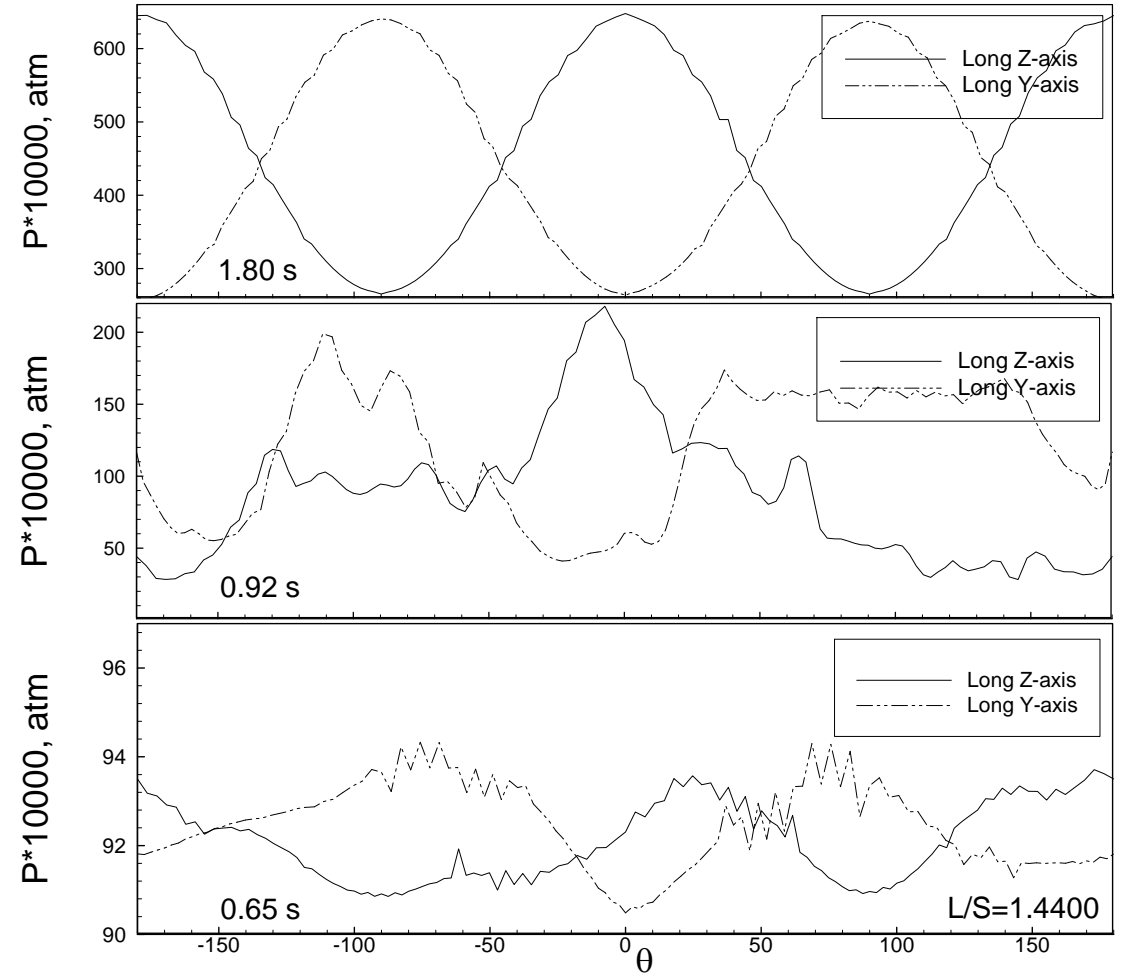

Fig. 11 Computed circumferential pressure profiles at different time slices during startup for the significantly out-of-round nozzle extension.

s. At $0.61 \mathrm{~s}$ into the startup transient, the Mach disk of the FSS Mach disk flow is not large enough to have the supersonic jet affecting the TEG flow, and vice versa. Until about $0.80 \mathrm{~s}$, the Mach disk is large enough and the TEG flow and the supersonic jet begins to attracting each other. At $0.848 \mathrm{~s}$, the supersonic jet and the TEG flow merge and PRSS Mach disk flow is formed. The Mach number contours at $0.865 \mathrm{~s}$ in Fig. 12 shows a typical PRSS Mach disk flow where the supersonic jet is partially attached to the nozzle extension and the reattachment is not continuous. At $0.925 \mathrm{~s}$, about $0.03 \mathrm{~s}$ before the occurrence of the separation line jump, the top separation line is slightly wavy, and the bottom reattachment line is continuous, hence this is a rare RSS Mach disk flow for this case. The separation line jump occurred at $0.928 \mathrm{~s}$ and it triggered a peak side load of $1738 \mathrm{~N}$. At $0.93 \mathrm{~s}$, or $0.02 \mathrm{~s}$ after the critical side load, the Mach disk flow is quite disturbed, and there are three discontinuous separation lines and two discontinuous reattachment lines. Note the shock stem (foot) jumped over the TEG exit ring on the xy-plane, and lagged behind the exit ring on the xz-plane. As a result, there is a partial separation line hidden behind the TEM 
torus on the xy-plane. That partial separation line is the residual of the top, wavy separation line at $0.925 \mathrm{~s}$ that had mostly jumped over the base formation of the TEG inlet and disappeared thereafter - or the remaining separation line of the splitting of the separation line mechanism [19]. Afterwards, sickle-shaped separation line emerged due to the deformation of the nozzle extension. That sickle-shaped separation line flow pattern was temporarily disrupted to become circular separation line flow pattern after the first PRSS-to-FSS transition (not shown), but resumed the formation at $1.095 \mathrm{~s}$ and maintained that formation until the nozzle extension was flowing full. The Mach number contours at $1.125 \mathrm{~s}$ time slice in Fig. 12 shows an initial sickle is growing at the two ends of the short axis. At $1.4 \mathrm{~s}$ into the startup transient, the sickle grows to its largest and the end of the sickle reaches the end of the nozzle extension.

A comparison of the computed peak side loads is summarized in Table 3, along with those computed in a previous study [19]. In this study, comparing to the peak side load of the nominal case, those have increased $57 \%$ and $60 \%$ for the slightly out-of-round cases, $50 \%$ and $55 \%$ for the more out-of-round cases, and $28 \%$ and $-18 \%$ for the significantly out-of-round cases. In previous study, comparing to the peak side load of the perfectly round case, that has increased $26 \%$ for the slightly out-of-round case, $55 \%$ for the more out-of-round case, and only $2.5 \%$ for the significantly out-ofround case. In general, the overall

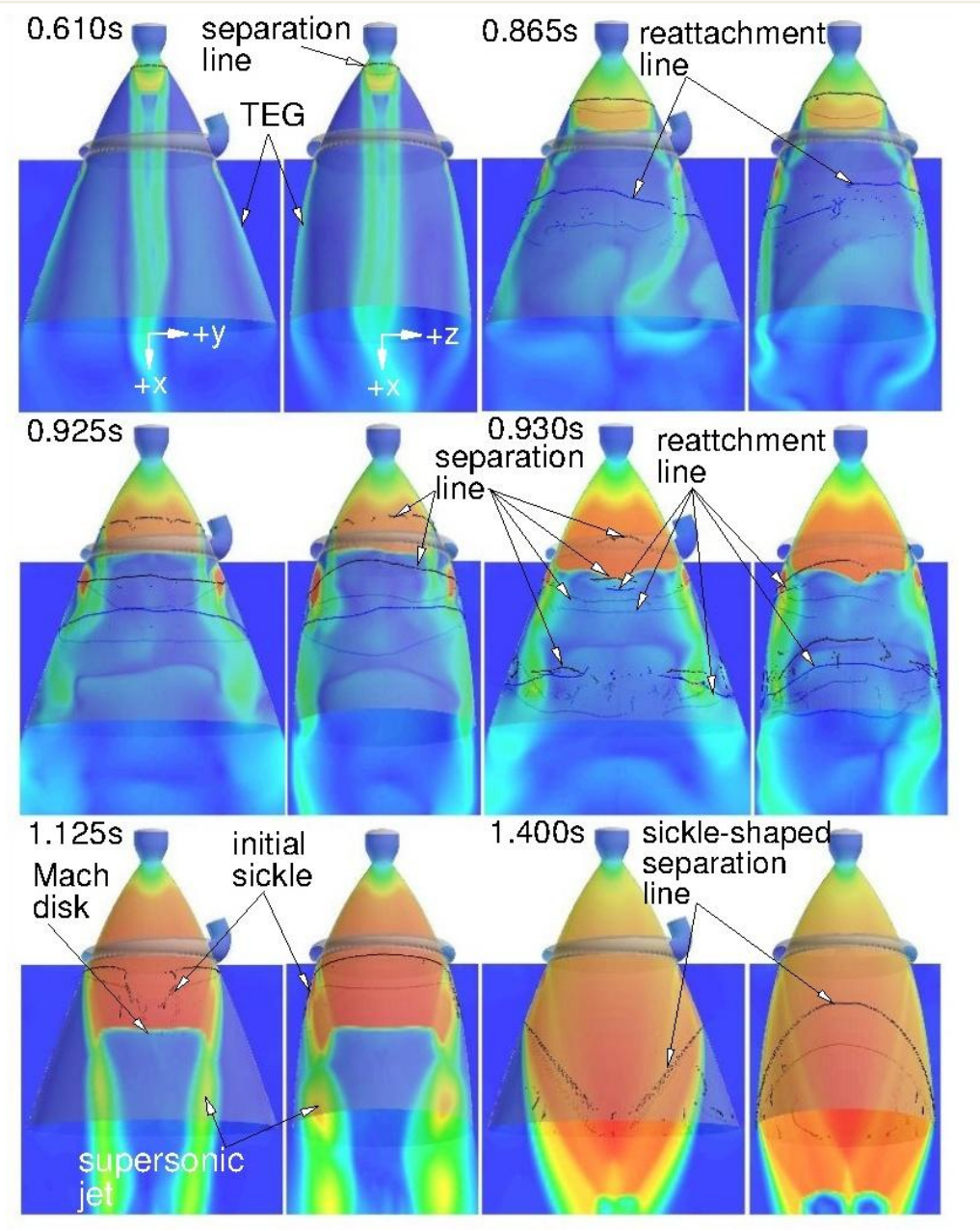

Fig. 12 Computed Mach number contours at different time slices during startup for the significantly out-of-round nozzle extension.

peak side loads culminated at the slightly out-of-round case in this study, and climaxed at the more out-of-round 
case in previous study. This is caused by the difference in the way the thrusters were ovalized, such that the flow instability overpowers the flow directionality at the slightly out-of-round case in this study, while that happens at the more out-of-round case in previous study.

Table 3. A comparison of the computed peak side loads, $\mathrm{kN}$

\begin{tabular}{|c|c|c|c|c|}
\hline Case & Description & Long axis & This study & Previous study \\
\hline nominal & perfectly round & - & $2114[19]$ & $2114[19]$ \\
\hline 1 & slightly out-of-round & $\mathrm{z}$ & $3309(+57 \%)$ & $2668(+26 \%)[19]$ \\
\hline 2 & slightly out-of-round & $\mathrm{y}$ & $3376(+60 \%)$ & - \\
\hline 3 & more out-of-round & $\mathrm{z}$ & $3175(+50 \%)$ & $3275(+55 \%)[19]$ \\
\hline 4 & more out-of-round & $\mathrm{y}$ & $3268(+55 \%)$ & - \\
\hline 5 & significantly out-of-round & $\mathrm{z}$ & $2715(+28 \%)$ & $2171(+2.7 \%)[19]$ \\
\hline 6 & significantly out-of-round & $\mathrm{y}$ & $1738(-18 \%)$ & - \\
\hline
\end{tabular}

Finally, the discussion would be incomplete without mentioning the study performed by Ostlund and Bigert [9]. They studied several non-round, polygon nozzles. Those polygon nozzles were not deformed nozzles, but purposely designed as faceted nozzles in order to reduce nozzle side loads. One of the side load reduction mechanisms pertinent to the current study is that the polygon corners acted as a kind of structure-breaker, splitting the flow separation pattern in the azimuthal direction. That mechanism, splitting the flow separation pattern, is essentially equivalent to the splitting of the separation line mechanism reported in previous study [19] for the significantly outof-round case, which also resulted in side load reduction. That agreement in side load reduction mechanism not only provided experimental evidence that the computed flow pattern [19] was credible, but also the mechanism itself is in agreement with the general theory developed in this study for out-of-round nozzles. In other words, splitting of the separation line [19] is the result of the increased flow directionality in the elongated side, made possible by the significant our-of-roundness over the entire thrust chamber [19] or over the nozzle extension as discussed in this study. Indeed, the faceted polygon nozzles provided increased flow directionality in the polygon corners, thereby stabilizing the inherently unstable flow in the original perfectly round nozzle, achieving nozzle side load reduction. 
In summary, the flow in the perfectly round case is inherently unstable, since there is no geometrical deformation to provide any flow directionality to stabilize the flow. In the mean time, any out-of-roundness, whether it is deformed in the entire thrust chamber, or the nozzle extension only, boosts the flow destabilization since any geometrical out-of-roundness exacerbates the flow asymmetry. On the other hand, any out-of-roundness also provides a flow directionality, which eventually stabilizes the flow. That is to say, the deformation generates two counteracting mechanisms, one destabilizes the flow that causes the side load goes higher, another stabilizes the flow that reduces the side load. In this effort, we see the flow destabilizing effect is stronger in the slightly out-ofround cases and the computed circumferential pressure profiles do not show discernible effect of flow directionality; In the more out-of-round cases, the flow stabilizing effect gains strength and we see obvious flow directionality in the computed circumferential pressure distributions at time slice of $1.80 \mathrm{~s}$; In the significantly out-of-round cases, the flow stabilizing effect grows strength and signs of flow directionality are noticeable in the computed circumferential pressure profiles in all three time slices.

\section{Conclusion}

Three-dimensional numerical computations were performed to determine the effect of out-of-round nozzle extension on nozzle side loads during engine start transient for a film cooled nozzle. The out-of-roundness was achieved with ovalization of the nozzle extension. Six cases were performed with three different degrees of ovalization on y and z axes: one slightly ovalized, one more ovalized and one significantly ovalized. It was found that the separation line jump is the critical side load physics for all cases. Comparing to the peak side load of the perfectly round nozzle, those of the slightly out-of-round cases increased by $57 \%$ and $60 \%$, those of the more out-ofround case increased by $50 \%$ and $55 \%$, and those of the significantly out-of-round cases increased by $28 \%$ and $18 \%$, for the elongation on the $\mathrm{z}$ - and $\mathrm{y}$-axis, respectively. For the significantly ovalized nozzle extension, the difference between the peak side loads of the two elongation cases comes from the location of the single TEG inlet duct, which resides on the y-axis.

Based on the observations from the results of this study and two other references, a general theory on the impact of geometrical deformation on the transient nozzle side loads is developed. That is, the deformation increases the flow instability in the nozzle, which increases the flow asymmetry and the nozzle side load. On the other hand, the deformation also increases the flow directionality, which decreases the flow instability and the nozzle side load. The 
final outcome between the two counteracting mechanisms depends not only on the degree of ovalization, but also on the specific type of deformations and design of nozzle. Under the circumstances of this effort, the flow instability overtakes the flow directionality in the slightly ovalized nozzle extension cases, while sign of flow directionality developed after nozzle extension flowing full in the more ovalized nozzle extension cases, and the flow directionality overcomes the flow instability in the significantly out-of-round nozzle extension cases.

\section{Acknowledgments}

This study was partially supported by the J-2X nozzle project of which Mike Shadoan is the manager, and by the J-2X system test project of which Marcus Neely is the manager, at the Marshall Space Flight Center (MSFC). The lead author wishes to thank James Beck of Pratt-Whitney Rocketdyne for his interest in this task. The lead author also wishes to acknowledge Yen-Sen Chen of Applied Research Laboratory, the original developer of the CFD code UNIC used in this study, for his continuous technical support. The fourth co-author wishes to thank Duc Nguyen and Danny Woo of Pratt-Whittney Rocketdyne for providing the engine design and transient sequencing information necessary to create the MSFC J-2X engine system model.

\section{References}

[1] Nave, L.H., and Coffey, G.A., "Sea Level Side Loads in High-Area-Ratio Rocket Engines,” AIAA Paper 73-1284, Nov. 1973.

[2] Cikanek, H.A., “Characteristics of Space Shuttle Main Engine Failures,” AIAA Paper 87-1939, June 1987.

[3] Watanabe, Y., Sakazume, N., and Tsuboi, M., "LE-7A Engine Nozzle Problems During the Transient Operations,” AIAA Paper 2002-3841, July 2002.

[4] Shi, J., "Rocket Engine Nozzle Side Load Transient Analysis methodology - A Practical Approach,” AIAA Paper 2005 1860, April 2005.

[5] Hagemann, G., Terhardt, M., Frey, M., Reijasse, P., Onofri, M., Nasuti, F., and Ostlund, J., "Flow Separation and SideLoads in Rocket Nozzles," $4^{\text {th }}$ International Symposium on Liquid Space Propulsion, March 12-15, 2000, DLR Lampoldshausen, pp. 1-19.

[6] Ruf, J., McDaniels, D.M., and Brown, A.M., "Nozzle Side Load Testing and Analysis at Marshall Space Flight Center," AIAA Paper 2009-4856, July 2009. 
[7] Wang, T.-S., “Transient Three-Dimensional Startup Side Load Analysis of a Regeneratively Cooled Nozzle,” Shock Waves - An International Journal on Shock Waves, Detonations and Explosions. Vol. 19, Issue 3, 2009, pp. 251 264. DOI: 10.1007/s00193-009-0201-2.

[8] Wang, T.-S., and Guidos, M., “Transient Three-Dimensional Side Load Analysis of a Film-Cooled Nozzle,” Journal of Propulsion and Power, Vol. 25, No. 6, 2009, pp. 1272-1280, doi: 10.2514/1.41025.

[9] Ostlund, J., and Bigert, M., “A Sub Scale Investigation Side Loads in Sea Level Rocket Nozzles,” AIAA Paper 99-2759, June, 1999.

[10] Ostland, J., "Supersonic Flow Separation with Application to Rocket Engine Nozzles," Doctoral Thesis, Royal Institute of Technology, Stockholm, Sweden, 2004.

[11] Deck, S., "Delayed Detached Eddy Simulation of the End-Effect Regime and Side-Loads in an Overexpanded Nozzle Flow," Shock Waves - An International Journal on Shock Waves, Detonations and Explosions. Vol. 19, Issue 3, 2009, pp. 239 249. DOI: 10.1007/s00193-009-0199-5.

[12] Hadjada, A., and Onofri, M., "Nozzle Flow Separation," Shock Waves - An International Journal on Shock Waves, Detonations and Explosions. Vol. 19, Issue 3, 2009, pp. 163 169. DOI: 10.1007/s00193-009-0209-7.

[13] Tomita, T., Takahashi, M., Sasaki, M., Sakamoto, H., Takahashi, M., Tamura, H., "Experimental Evaluation of Side Loads in LE-7A Prototype Engine Nozzle," Shock Waves - An International Journal on Shock Waves, Detonations and Explosions. Vol. 19, Issue 3, 2009, pp. 213 228. DOI: 10.1007/s00193-009-0191-0.

[14] Nguyen, A.T., Deniau, H., Girard, S., and De Roquefort, T.A., "Unsteadiness of Flow Separation and End-Effects Regime in a Thrust-Optimized Contour Rocket Nozzle,” Flow, Turbulence and Combustion, Vol. 71, 2003, pp.161-181.

[15] Deck S., and Guillen, P., "Numerical Simulation of Side loads in an Ideal Truncated Nozzle," Journal of Propulsion and Power, Vol. 18, No. 2, 2002, pp. 261-269.

[16] Shimizu, T., Miyajima, H., and Kodera, M., "Numerical Study of Restricted Shock Separation on a Compressed Truncated Perfect Nozzle,” AIAA Journal, Vol. 44, No. 3, 2006, pp. 576-584.

[17] Kwan, W., and Stark, R., "Flow Separation Phenomena in Subscale Rocket Nozzles," AIAA Paper 2002-4229, July 2002.

[18] Reijasse, Ph., and Boccaletto, L., "Influence of Film Cooling on Nozzle Side loads,” AIAA Paper 2008-392, Jan. 2008.

[19] Wang, T.-S., Lin, J., Ruf, J., and Guidos, M., “Transient Three-Dimensional Side Load Analysis of Out-of-Round Film Cooled Nozzles," Journal of Propulsion and Power, Vol. 27, No. 4, July-August, 2011, pp. 899-907, doi: 10.2514/1.B34082.

[20] Wang, T.-S., "Multidimensional Unstructured-Grid Liquid Rocket Engine Nozzle Performance and Heat Transfer Analysis," Journal of Propulsion and Power, Vol. 22, No. 1, January-February, 2006, pp. 78-84.

[21] Shang, H.M., and Chen, Y.-S., "Unstructured Adaptive Grid method for Reacting Flow Computation," AIAA Paper 
1997-3183, July 1997.

[22] Wang, T.-S., Chen, Y.-S., Liu, J., Myrabo, L.N., and Mead, F.B. Jr., "Advanced Performance Modeling of Experimental Laser Lightcraft,” Journal of Propulsion and Power, Vol. 18, No. 6, 2002, pp. 1129-1138.

[23] Chang, G., Ito, Y., Ross, D., Chen. Y.-S., Zhang S., and Wang, T.-S., "Numerical Simulations of Single Flow Element in a Nuclear Thermal Thrust Chamber” AIAA Paper 2007-4143, June 2007.

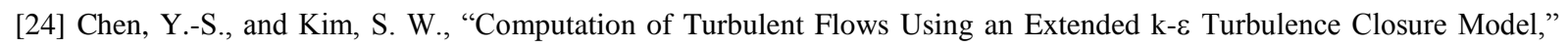
NASA CR-179204, Oct. 1987.

[25] Wang, T.-S., Droege, A., D’Agostino, M., Lee, Y.-C., and Williams, R., “Asymmetric Base-Bleed Effect on X-33 Aerospike Plume Induced Base-Heating Environment,” Journal of Propulsion and Power, Vol. 20, No. 3, 2004 , pp. $385-393$.

[26] Chen, Y.-S., Cheng, G.C., and Farmer, R.C., "Reacting and Non-Reacting Flow Simulation for Film Cooling in 2-D Supersonic Flows,” AIAA Paper 92-3602, July 1992.

[27] Wang, T.-S., Canabal, F., Chen, Y.-S., and Cheng, G.C., "Multiphysics Computational Analysis of a Solid-Core Nuclear Thermal Engine Thrust Chamber,” Journal of Propulsion and Power, Vol. 26, No. 3, May-June, 2010, pp. 407-414.

[28] Svehla, R.A., and McBride, B.J., "FORTRAN IV Computer Program for Calculation of Thermodynamic and Transport Properties of Complex Chemical Systems,” NASA TN D-7056, Jan. 1973.

[29] Steinbrenner, J.P., Chawner, J.R., and Fouts, C., "Multiple Block Grid Generation in the interactive Environment," AIAA Paper 90-1602, June 1990.

[30] Wang, T.-S., Lin, J., Ruf, J., Guidos, M., and Cheng, G.C., "Effect of Coolant Flow Distribution on Transient Side Load Analysis of Film Cooled Nozzles," AIAA Paper 2011-3268, June 2011, accepted for publication by Journal of Propulsion and Power.

[31] Tomita, T., Takahashi, M., Sasaki, M., Takahashi, M., Tamura, H., Watanabe, Y., and Tsuboi, M., “ Parametric Study on the Influence of a Discontinuous Step in a Nozzle Contour on Side-Load,” AIAA Paper 2003-4764, July 2003.

[32] Wonezawa, K., Yokota, K., Tsujimoto, K., Sakazume, N., and Watanabe, Y., "Three-Dimensional Unsteady Flow Simulation of Compressed Truncated Perfect nozzles,” AIAA Paper 2002-3991, July 2002. 


\section{Transient Side Load Analysis of Out-of-Round Film-Cooled Nozzle Extensions}

Ten-See Wang, Jeff Lin, Joe Ruf and Mike Guidos

NASA Marshall Space Flight Center, Huntsville, Alabama

48th AIAA/ASME/SAE/ASEE Joint Propulsion Conference and Exhibit July 31, 2012

102-LP-12 Side Loads 10:00 AM - 10:30 AM 


\section{Acknowledgement}

- This work was partially supported by the J-2X engine program at NASA MSFC. Support by Mike Shadoan of Combustion Devices and Marcus Neely of Engine Systems Test are appreciated.

- The employed CFD code, UNIC, was originally developed and continuously improved by Dr. Yen-Sen Chen

- Interest from James Beck of Pratt-Whitney Rocketdyne in this work is acknowledged 


\section{What is nozzle side load?}

- Nozzle side load is a lateral force occurring naturally during transient startup and shutdown of rocket engines

- Nozzle side loads are detrimental to the engine components such as actuator, cooling tubes, propellant feed lines, etc. for almost all rocket engines during development

- For regeneratively cooled engines, such as SSME, the origins of the side loads have been identified as combustion wave, shock transitions, and shock breathing at the nozzle exit

- For film cooled engines, such as LE-7A and J-2X, the origins of side loads have been identified as shock transitions, and flow separation line jump over the turbine exhaust gas (TEG) flow 


\section{J-2X Engine}

- J-2X engine, the Ares I upper stage engine under development, is an evolved variation of two historic predecessors: the J-2 and J-2S engines.

- It has a regeneratively cooled combustion chamber and nozzle, along with a film-cooled nozzle extension.

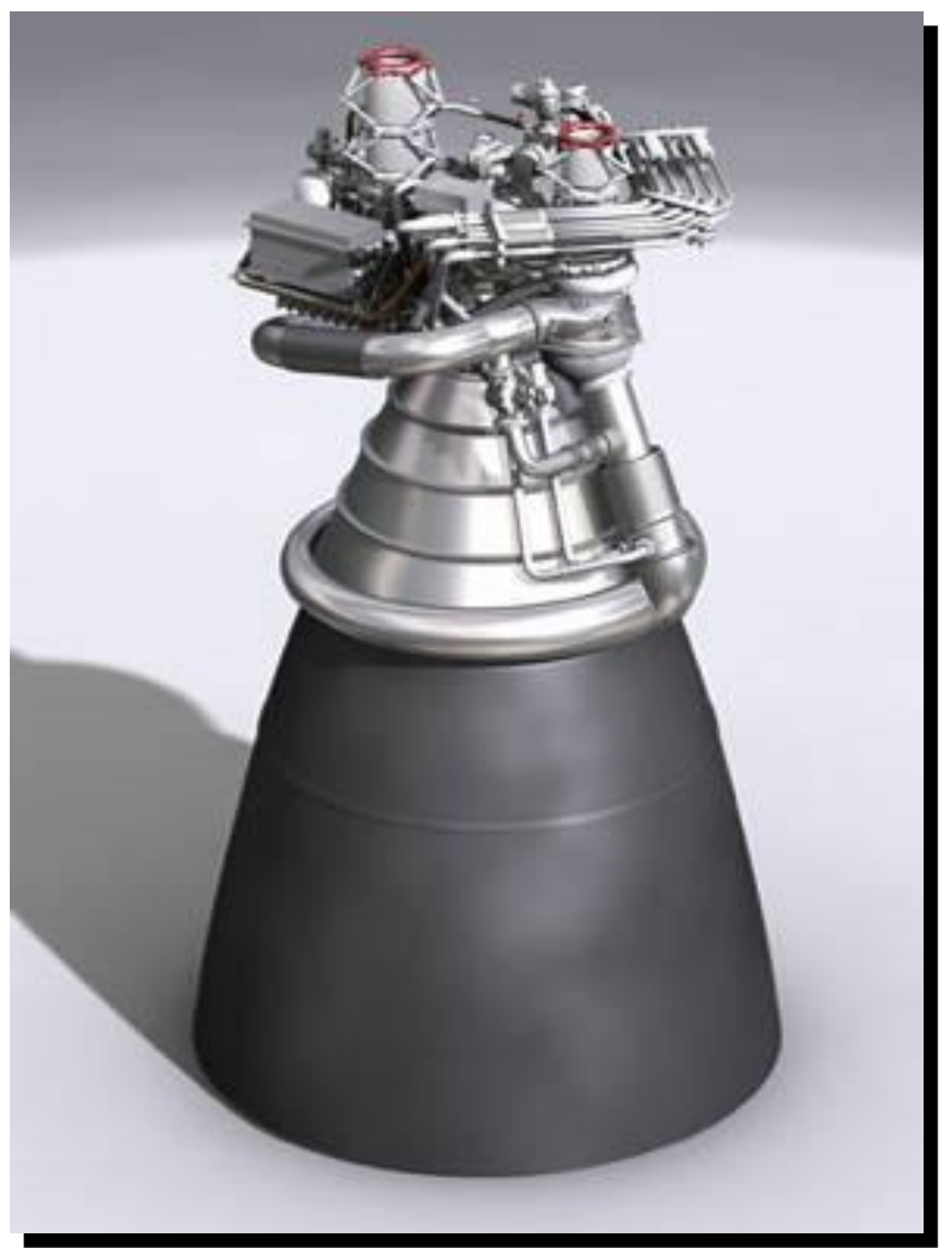




\section{Nozzle Out-of-Roundness}

- Large, relatively light weight, liquid rocket engine nozzles, are probably never truly round.

- The causes of nozzle out-of-roundness could be, but are not limited to, long term internal stresses, especially high thermal load during hot-fire test, such as creep. 


\section{Objective}

- To computationally investigate the effect of out-of-round nozzle extension on the nozzle side load during the $\mathrm{J}-2 \mathrm{X}$ engine startup transient. 


\section{Computational Methodology}

- Multidisciplinary computational methodology:

- UNIC is a unstructured-grid, pressure-based, reacting flow, CFD \& heat transfer solver

- Engine system modeling for transient inlet properties (to simulate hot-firing tests)

- Thermal modeling of wall temperatures for combustion chamber, nozzle, and nozzle extension (to simulate hotfiring tests) 

during Sea Level Startup

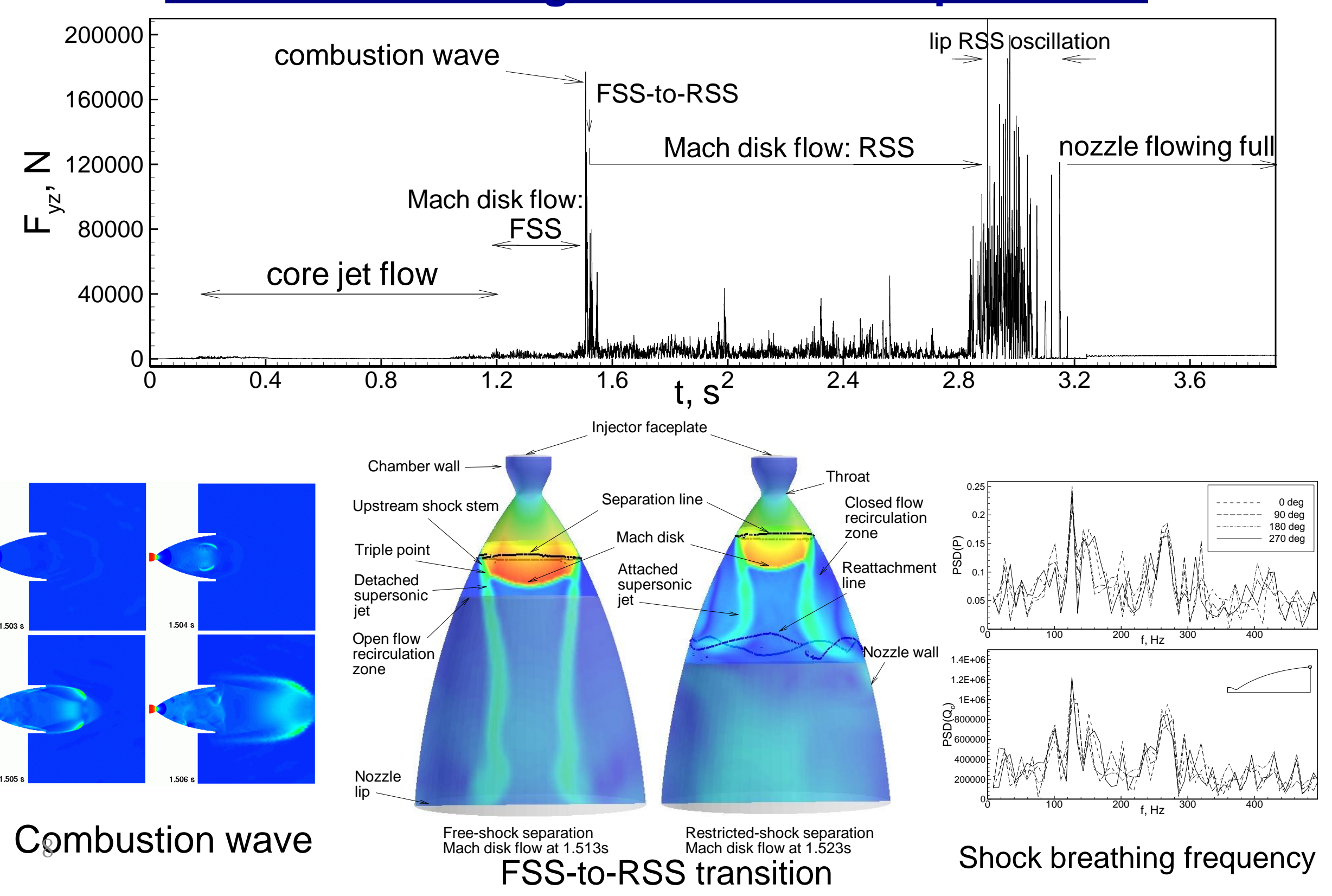




\section{Benchmark with Regeneratively Cooled SSME Nozzle}

\section{During Sea Level Startup}

\begin{tabular}{|c|c|c|c|c|c|}
\hline \multicolumn{3}{|c|}{$\mathrm{Fyz}, \mathrm{kN}$} & \multicolumn{2}{|c|}{ Dominant frequencies, Hz } & Physics \\
\hline & Test & CFD & Test & CFD & \\
\hline $1^{\text {st }}$ jump & 90 & 80 & - & - & $\begin{array}{c}\text { FSS-to-RSS } \\
\text { transition }\end{array}$ \\
\hline $2^{\text {nd }}$ jump & 200 & 212 & 120 & 122 & RSS breathing \\
\hline
\end{tabular}




\section{Comparison of J-2X Sea Level Results with those of LE-7A}

- Watanabe's LE-7A hot-fire Tests at sea level (Watanabe, Yasuhide, et al., "LE7A Engine Nozzle Problems during the Transient Operations," AIAA Paper 2002-3841).

- Measured the transient side loads of LE-7A engine with and without the nozzle extension

- Reported that peak side load was caused by the separation line jump

- Found out the side load of the stub nozzle

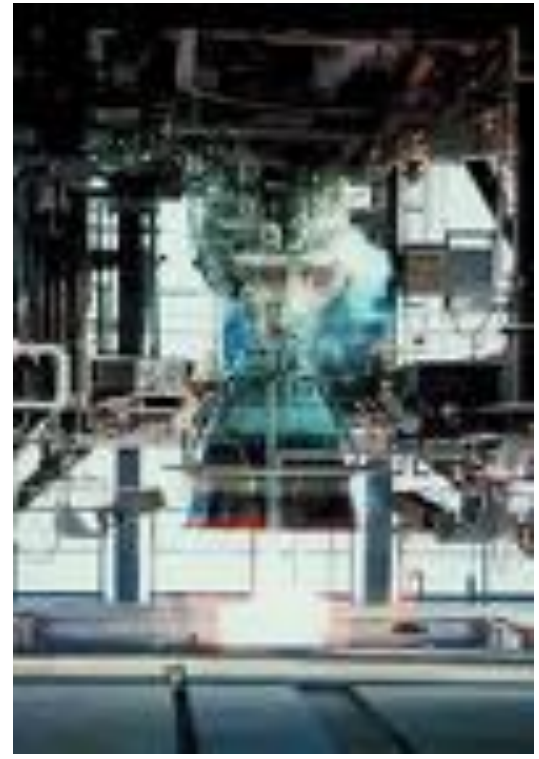
was reduced drastically. 


\section{Comparison of Computed J-2X (Nozzlette) with those of LE-7A Hot-Fire Test}

\section{Comparison of the Sea Level Peak Side Loads}

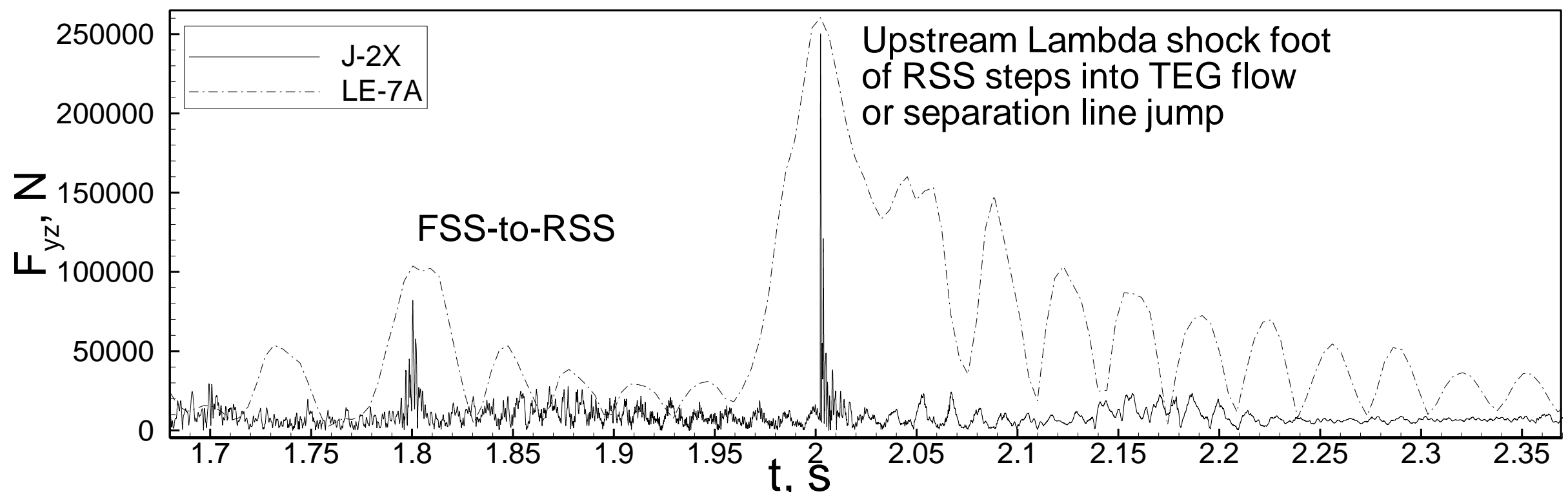

\begin{tabular}{|l|l|c|c|l|}
\hline \multicolumn{2}{|l|}{ Side load, $\mathrm{kN}$} & $\mathrm{J}-2 \mathrm{X}$ & LE-7A & physics \\
\hline \multirow{2}{*}{$\begin{array}{l}\text { With } \\
\text { extension }\end{array}$} & $1^{\text {st }}$ peak & 80 & 102 & Shock transition \\
\cline { 2 - 5 } & $2^{\text {nd }}$ peak & 249 & 259 & Separation line jumping \\
\hline \multirow{2}{*}{$\begin{array}{l}\text { Without } \\
\text { extension }\end{array}$} & $1^{\text {st }}$ peak & 26 & 45 & Shock transition \& breathing \\
\cline { 2 - 5 } & $2^{\text {nd }}$ peak & - & - & \\
\hline
\end{tabular}




\section{A Grid Layout of the J-2X Nozzle}

\begin{tabular}{|c|c|c|}
\hline Engine & Grid size & $\begin{array}{c}\text { Circumferential } \\
\text { division number }\end{array}$ \\
\hline SSME & $1,275,120$ & 72 \\
\hline $\begin{array}{c}\text { J-2X } \\
\text { Nozzlette }\end{array}$ & 2.058192 & 72 \\
\hline $\begin{array}{c}\text { J-2X TEM } \\
\text { J-2X TEM } \\
\text { \& Duct }\end{array}$ & $4,421,166$ & 120 \\
\hline
\end{tabular}
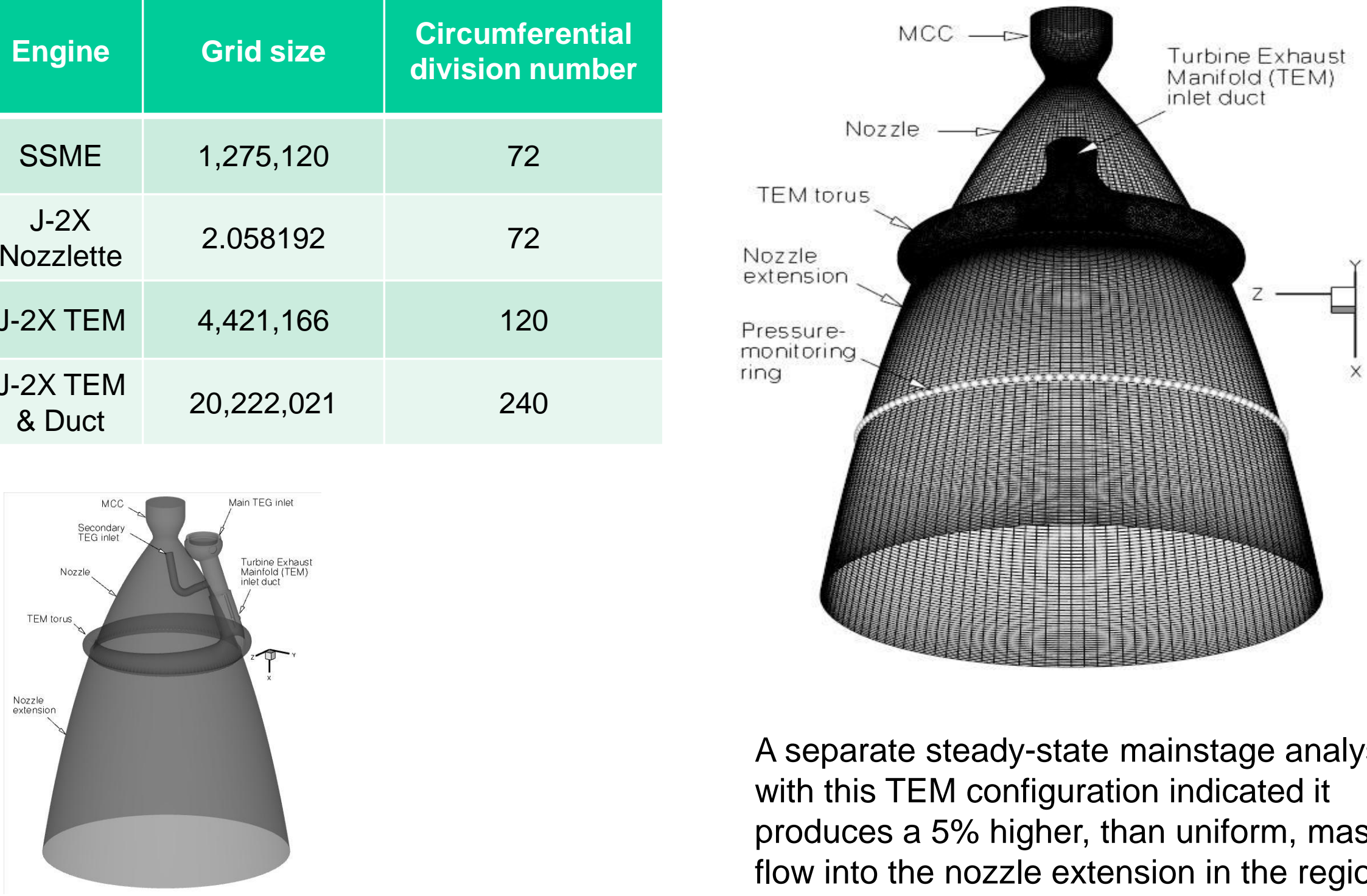

A separate steady-state mainstage analysis with this TEM configuration indicated it produces a $5 \%$ higher, than uniform, mass flow into the nozzle extension in the region under the TEM inlet duct. 


\section{Cross-Sectional View of the Six Ovalized Thrusters}
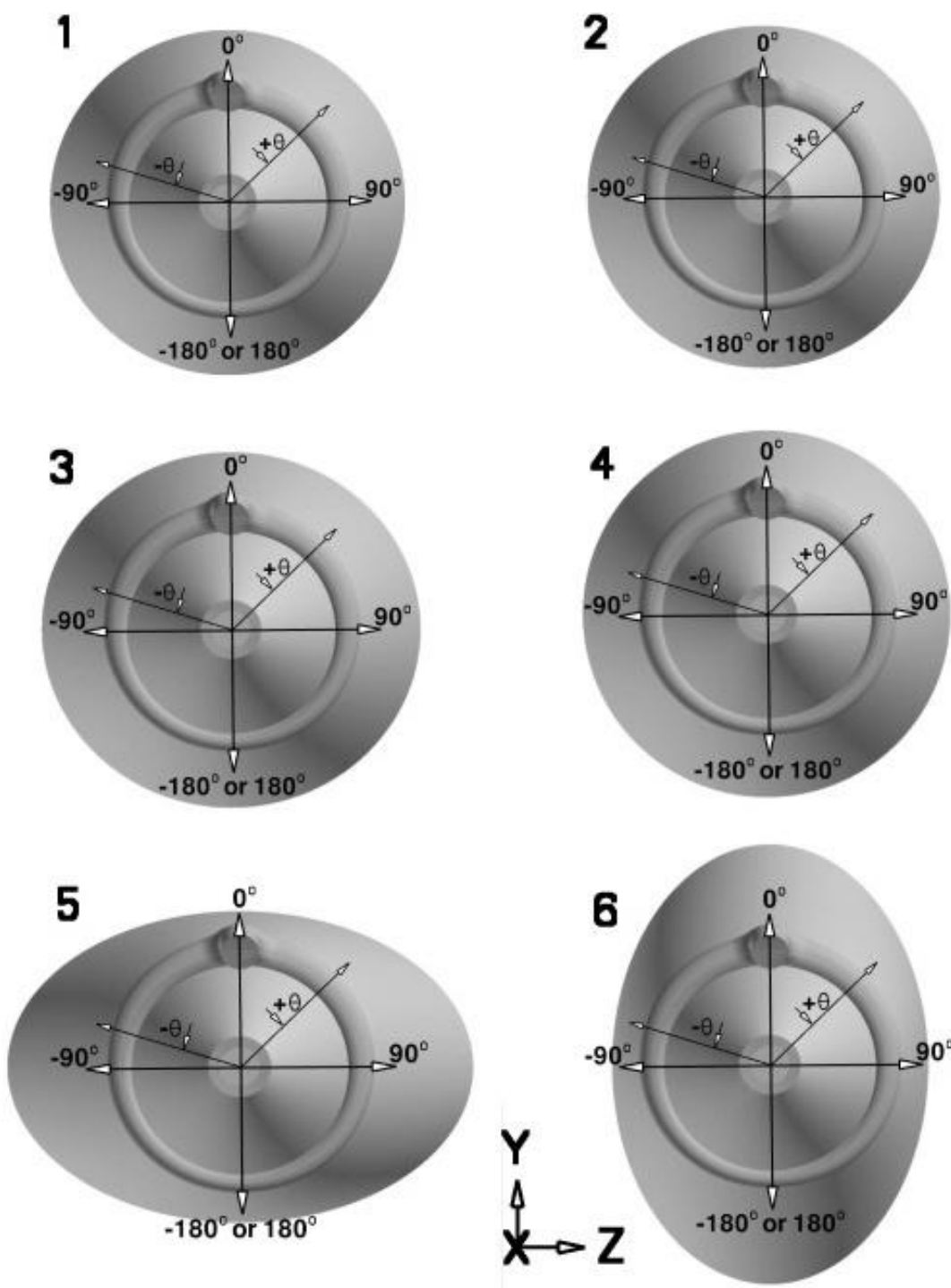


\section{Run Matrix}

\begin{tabular}{|c|c|c|c|c|c|}
\hline Case & Description & L/S ratio & Deformation, in & Long axis & Ref. \\
\hline baseline & perfectly round & 1.0000 & \pm 0.00 & - & 19,30 \\
\hline 1 & slightly out-of-round & 1.0086 & \pm 0.25 & $\mathrm{Z}$ & this work \\
\hline 2 & slightly out-of-round & 1.0086 & \pm 0.25 & Y & this work \\
\hline 3 & more out-of-round & 1.0346 & \pm 1.00 & $\mathrm{Z}$ & this work \\
\hline 4 & more out-of-round & 1.0346 & \pm 1.00 & Y & this work \\
\hline 5 & $\begin{array}{l}\text { significantly out-of- } \\
\text { round }\end{array}$ & 1.4400 & \pm 11.6 & Z & this work \\
\hline 6 & $\begin{array}{l}\text { significantly out-of- } \\
\text { round }\end{array}$ & 1.4400 & \pm 11.6 & $\mathrm{Y}$ & this work \\
\hline
\end{tabular}




\section{Transient Startup Inlet Flow Properties of MCC and TEG}

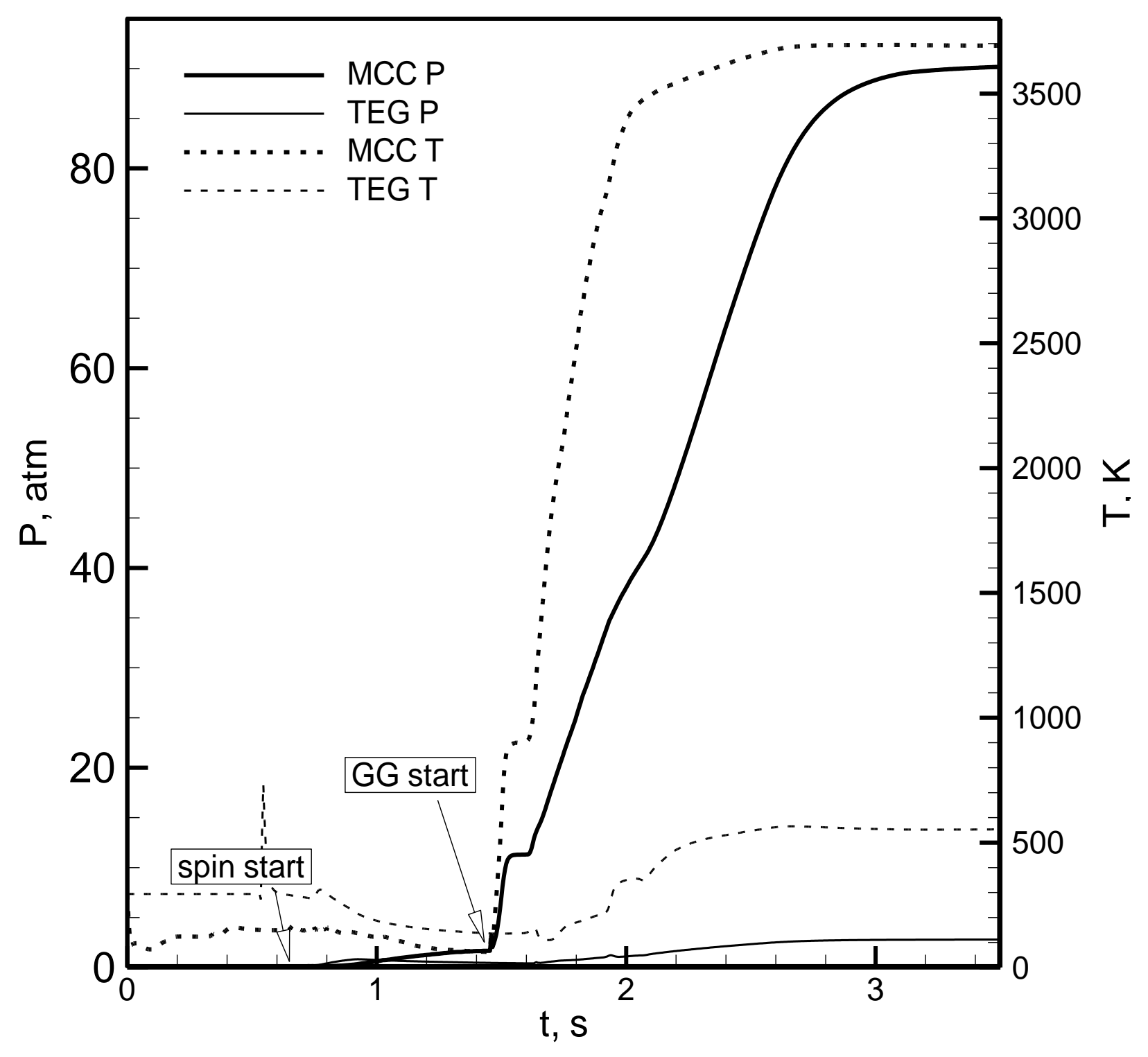




\section{Computed Side Load History for Nominal Case}

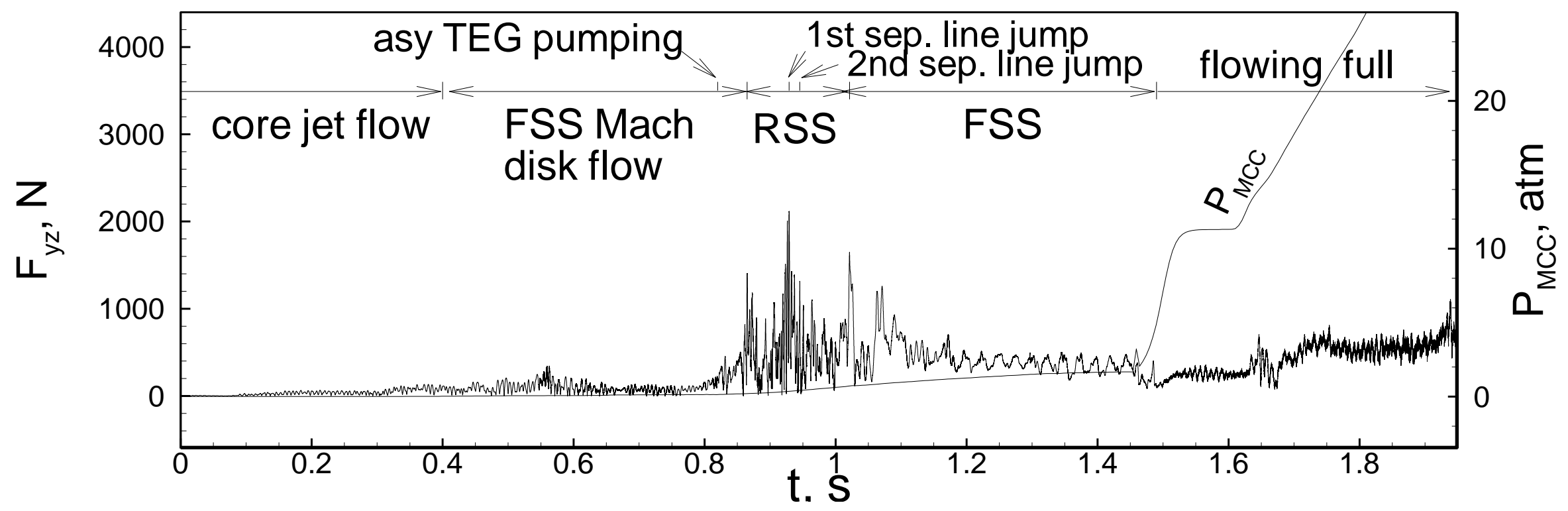




\section{Computed Side Load History for Nominal Case}

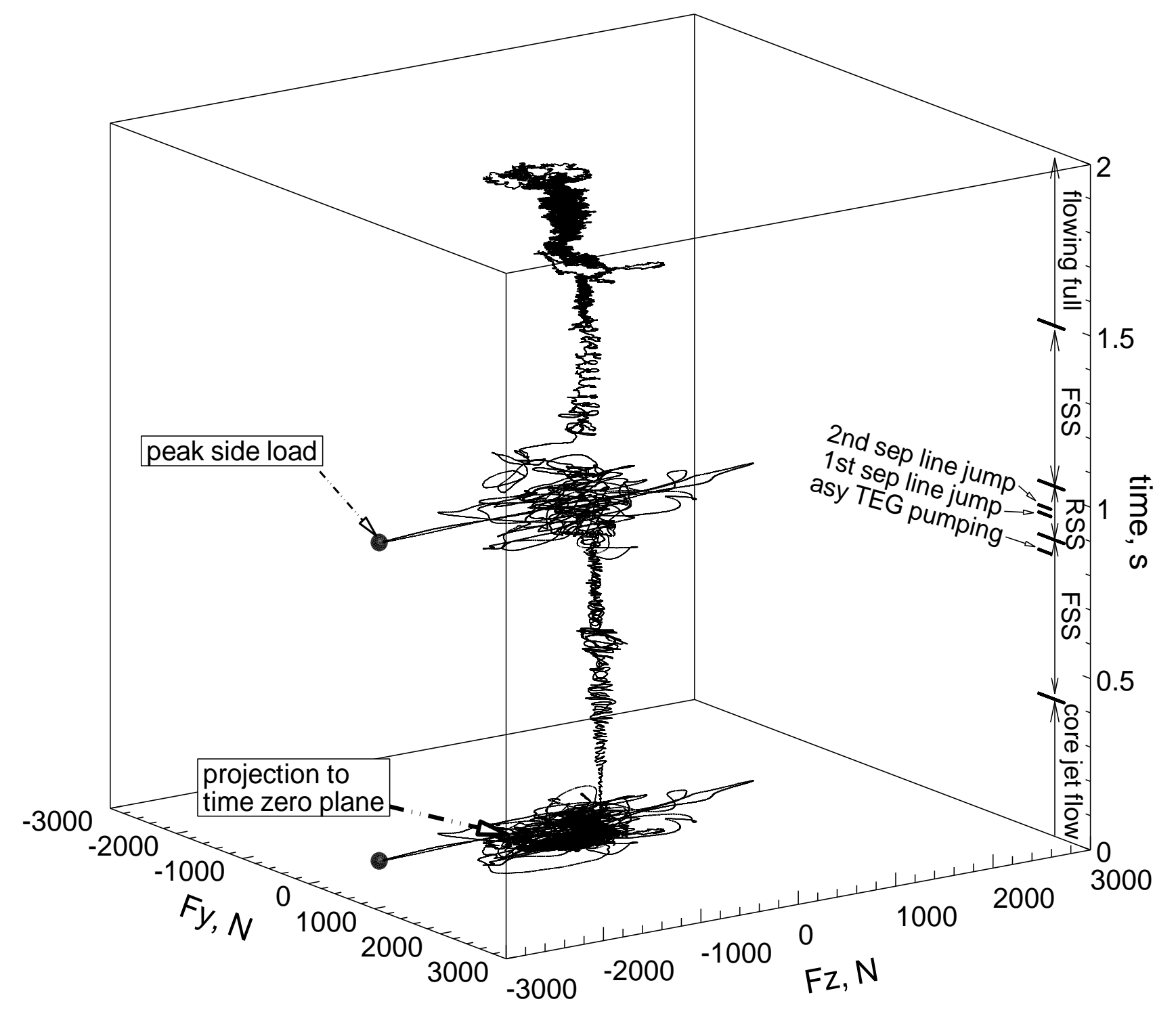


Mach Number Contours at Selected Time Slices for Nominal Case

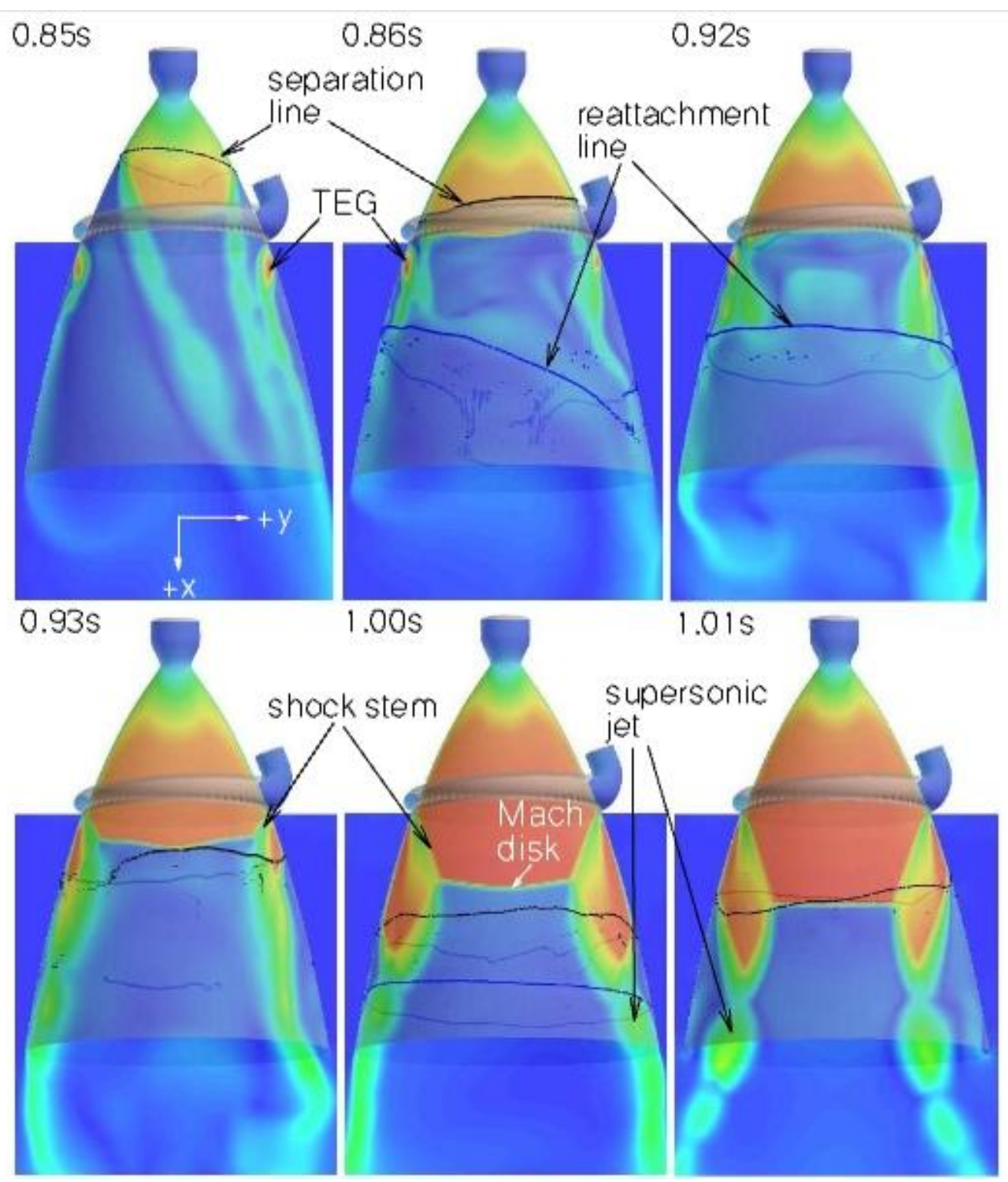




\section{Circumferential Pressure Profiles - Baseline Case}

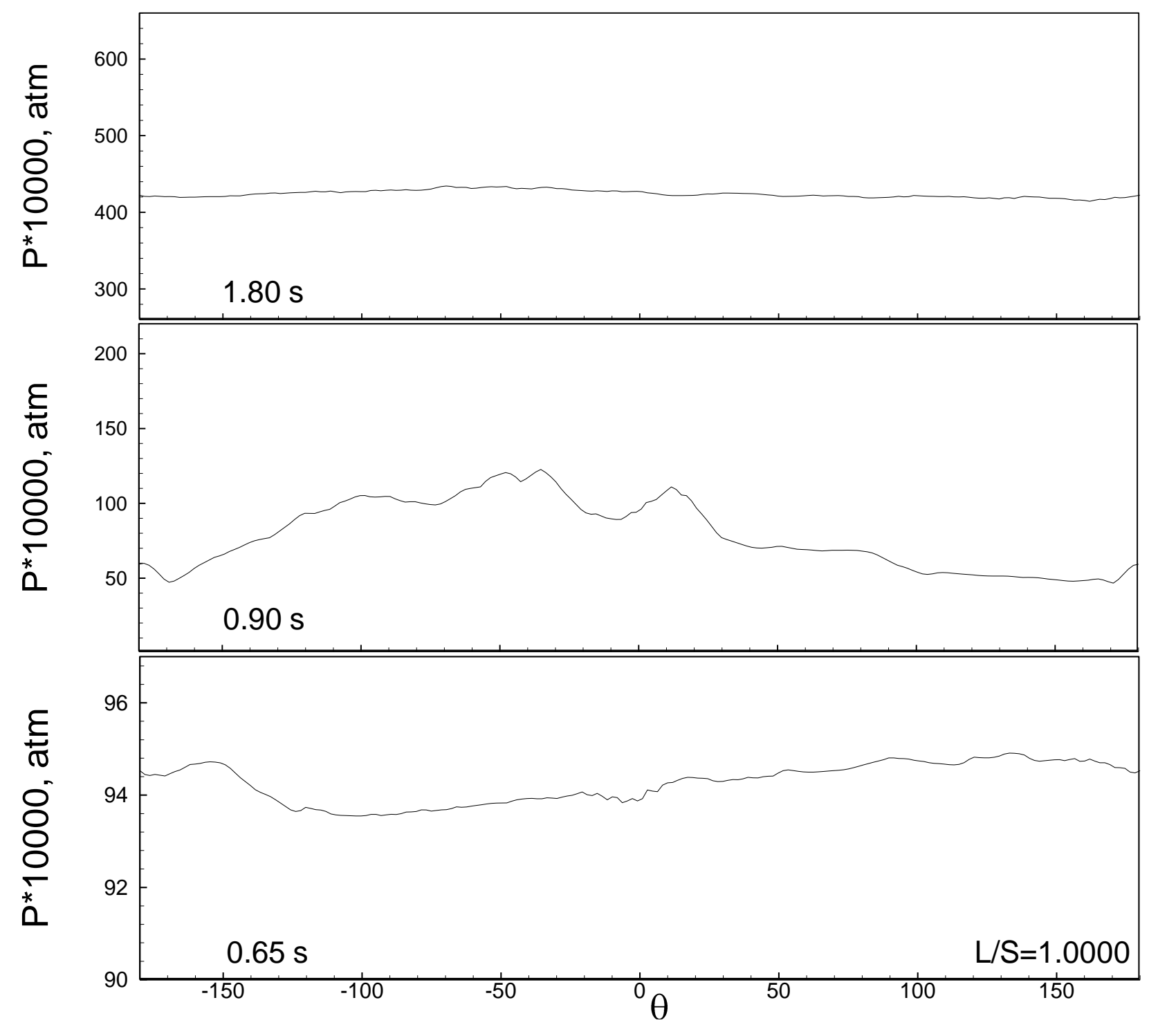


Slightly Overalized Nozzle Extensions

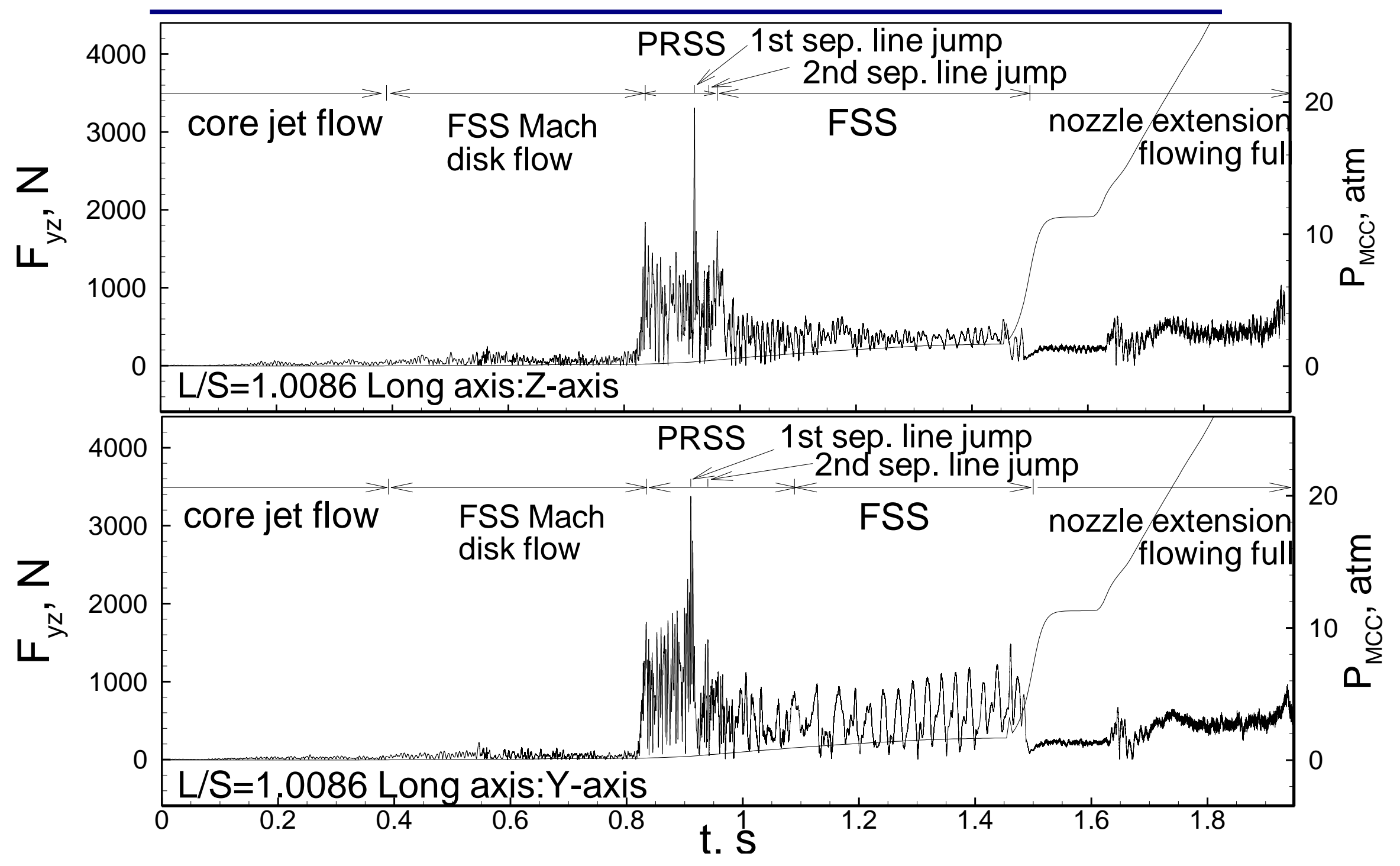


Computed Circumferential pressure Histories for Slightly Overalized Nozzle Extensions

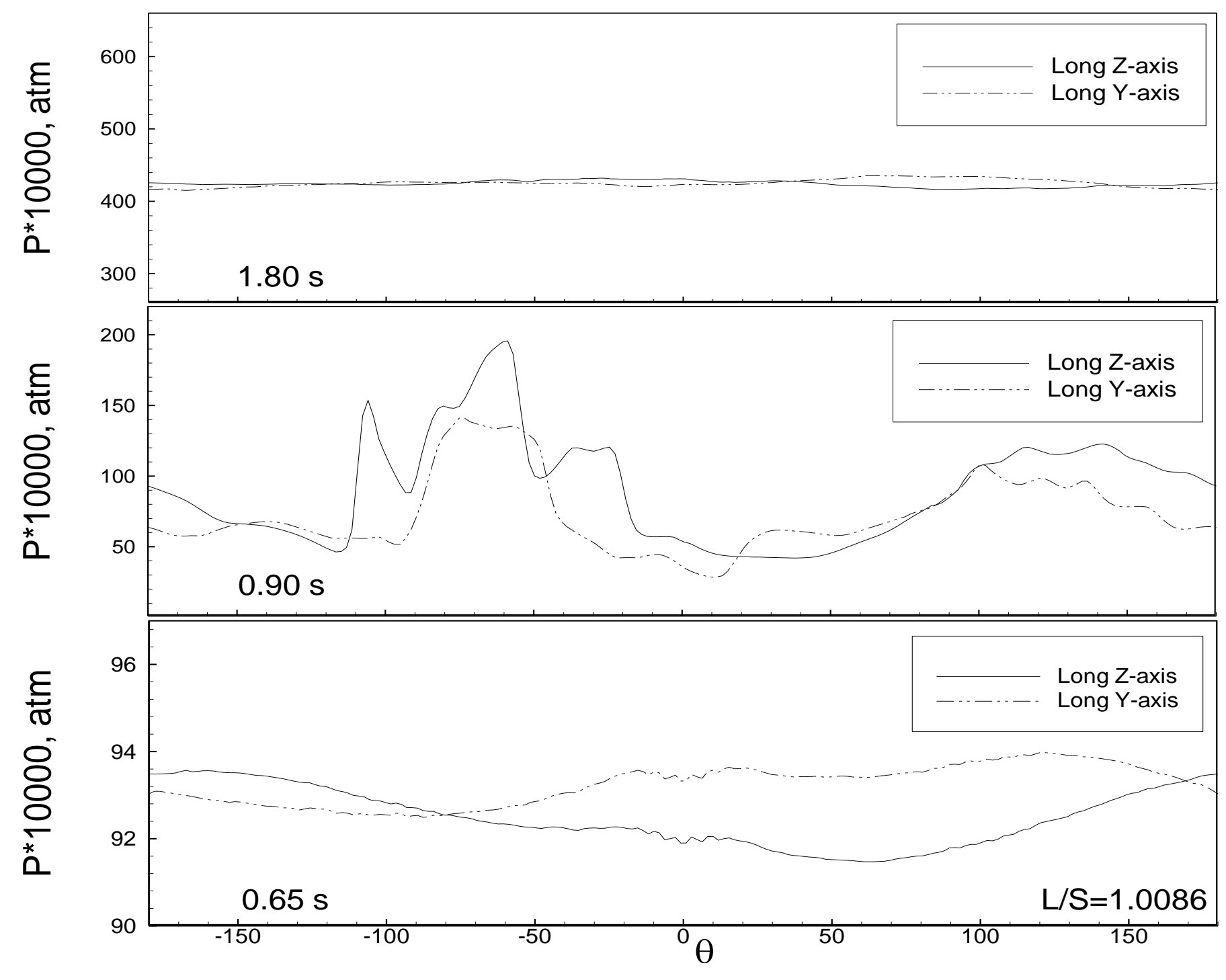


Computed Side Load Histories for

More Ovalized Nozzle Extensions

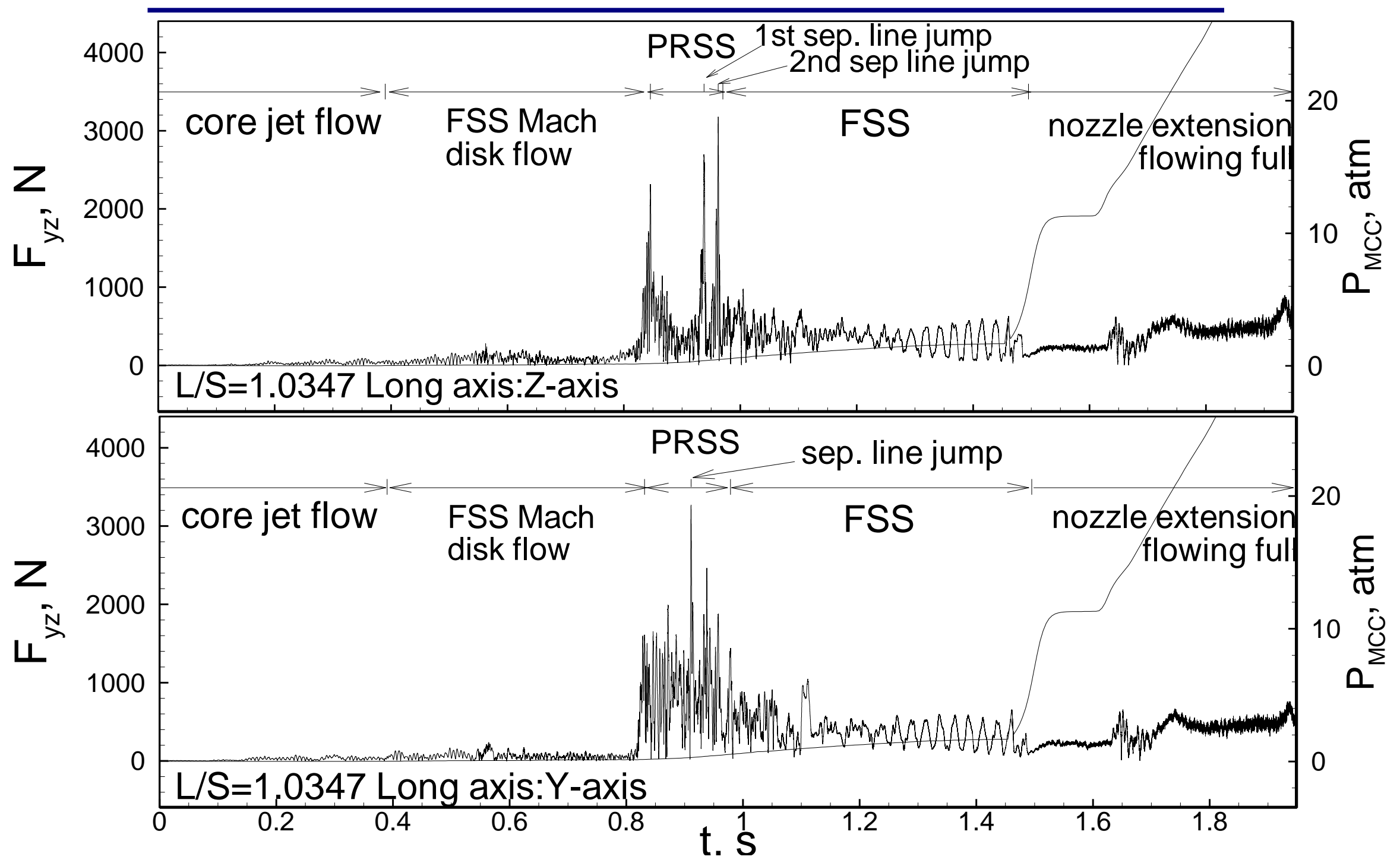



for More Overalized Nozzle Extensions

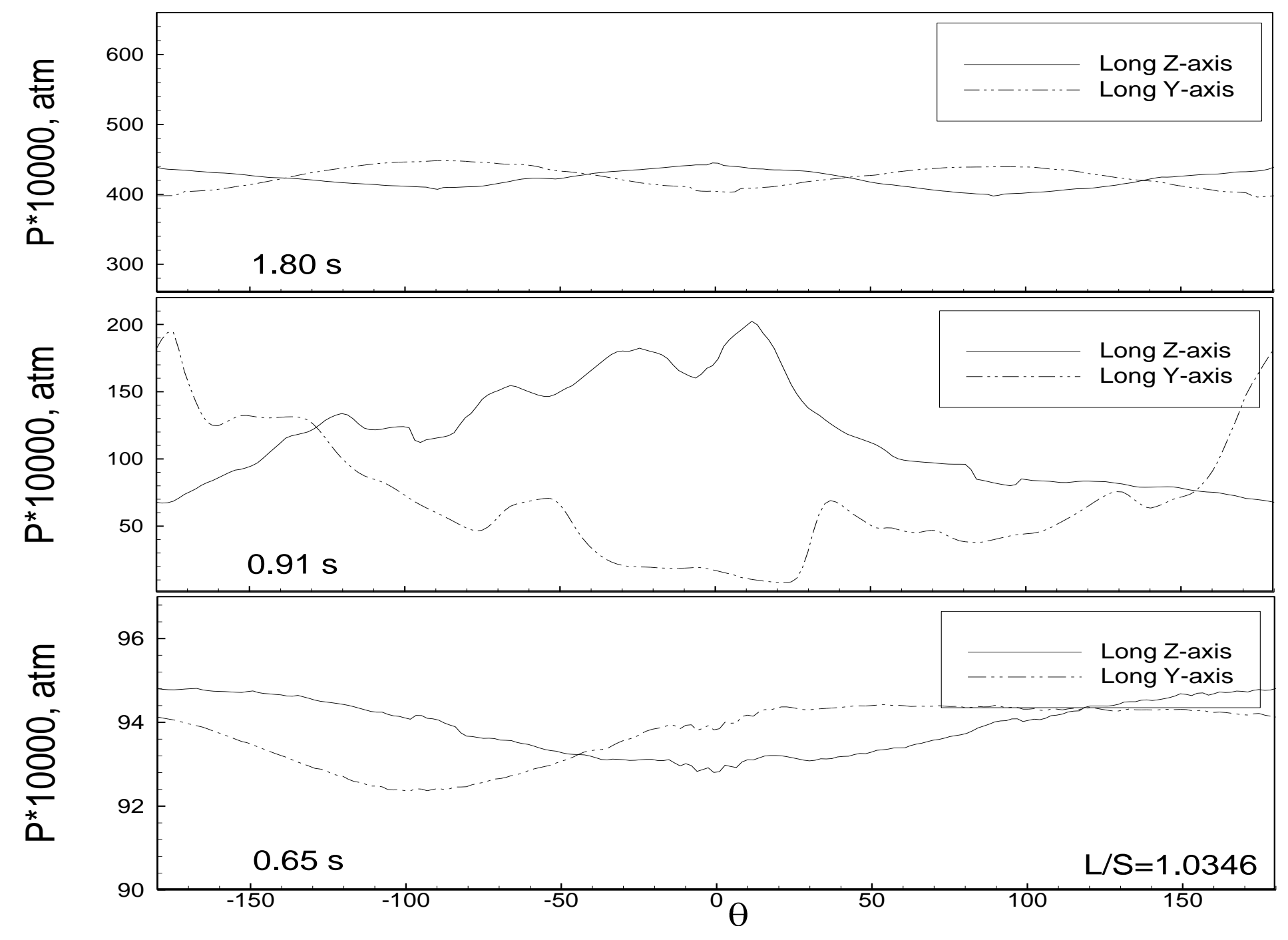



Significantly Ovalized Nozzle Extension

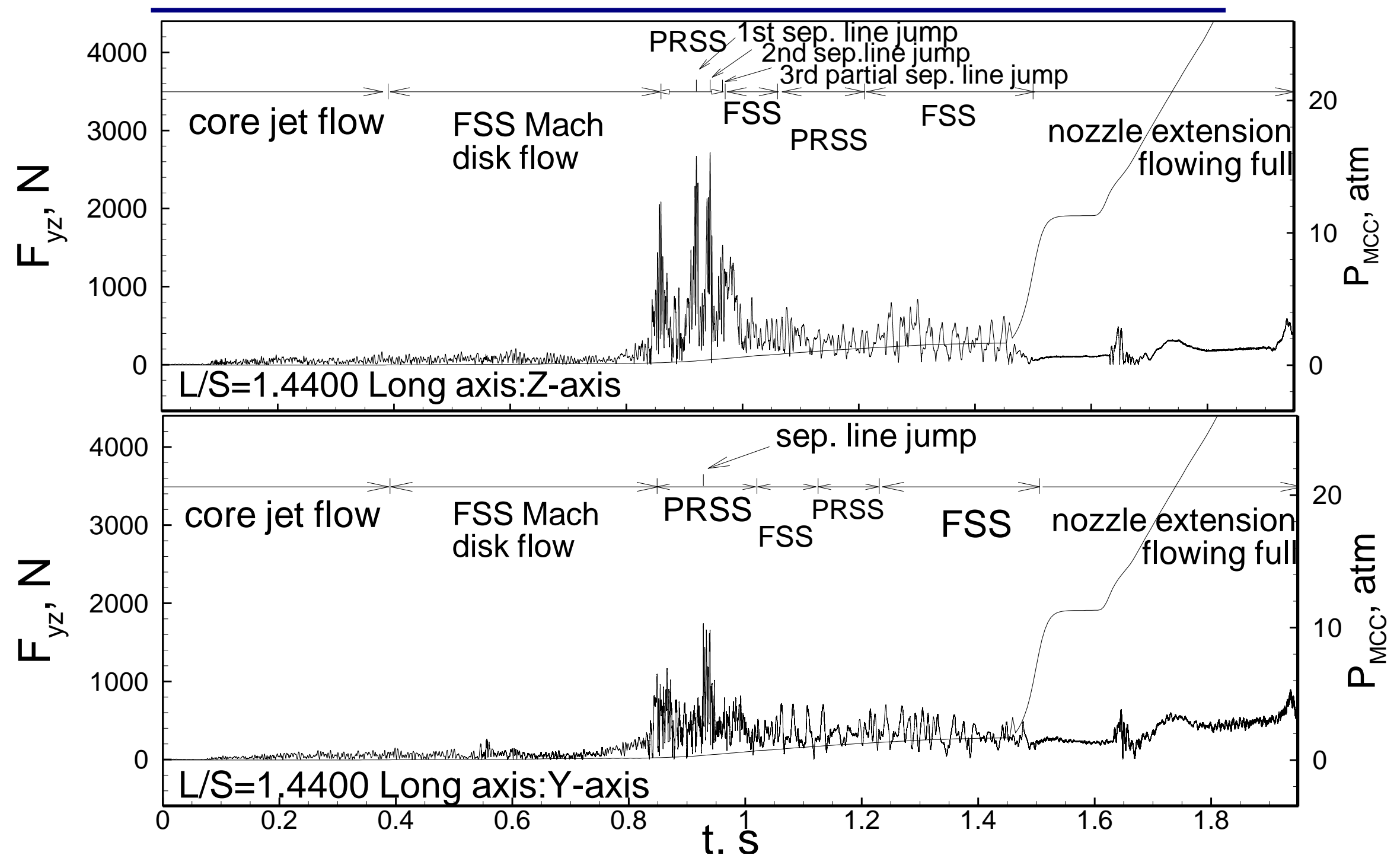


Computed circumferential pressure Histories for Significantly Overalized Nozzle Extensions

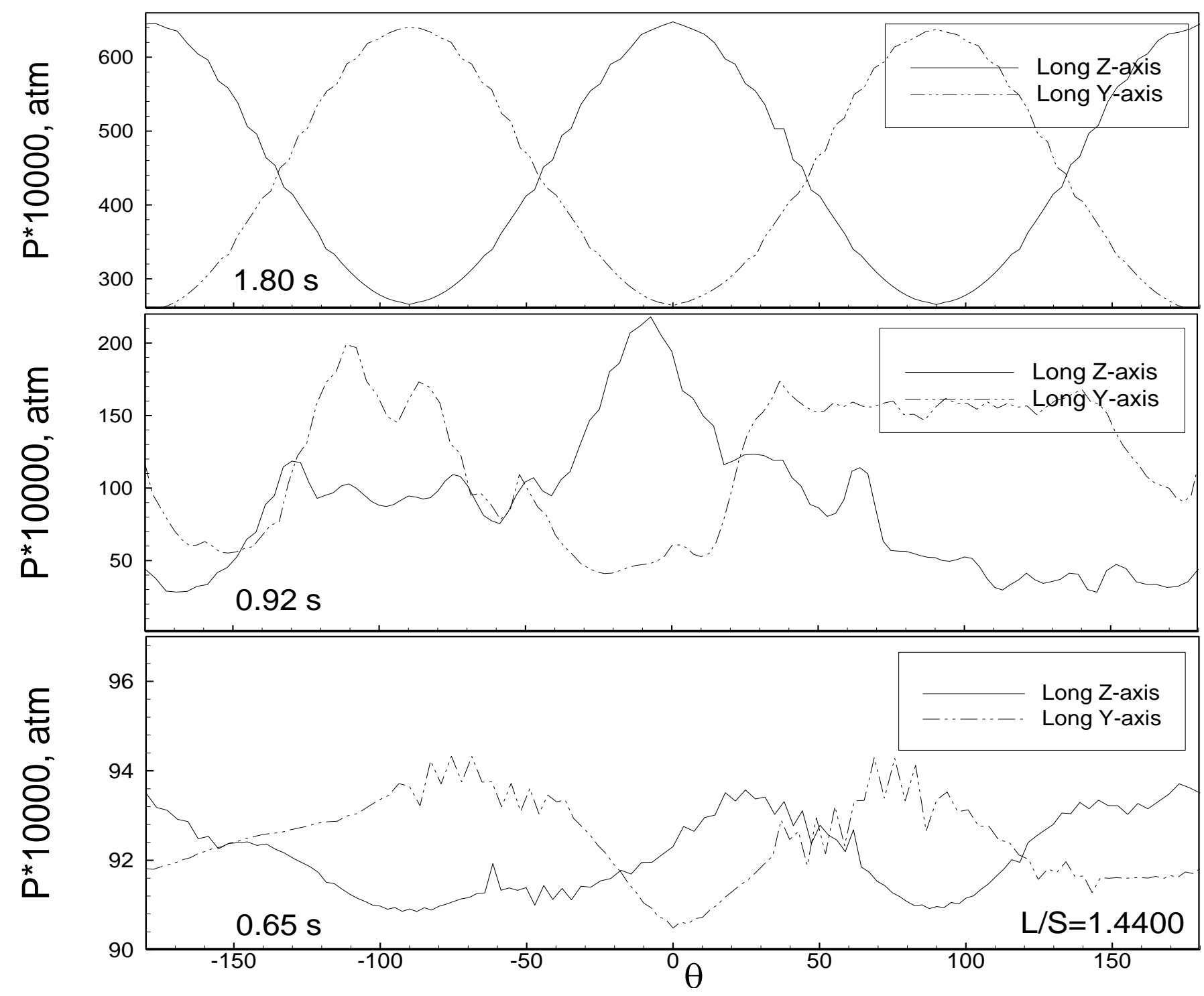




\section{for Significantly Overalized Nozzle Extensions}

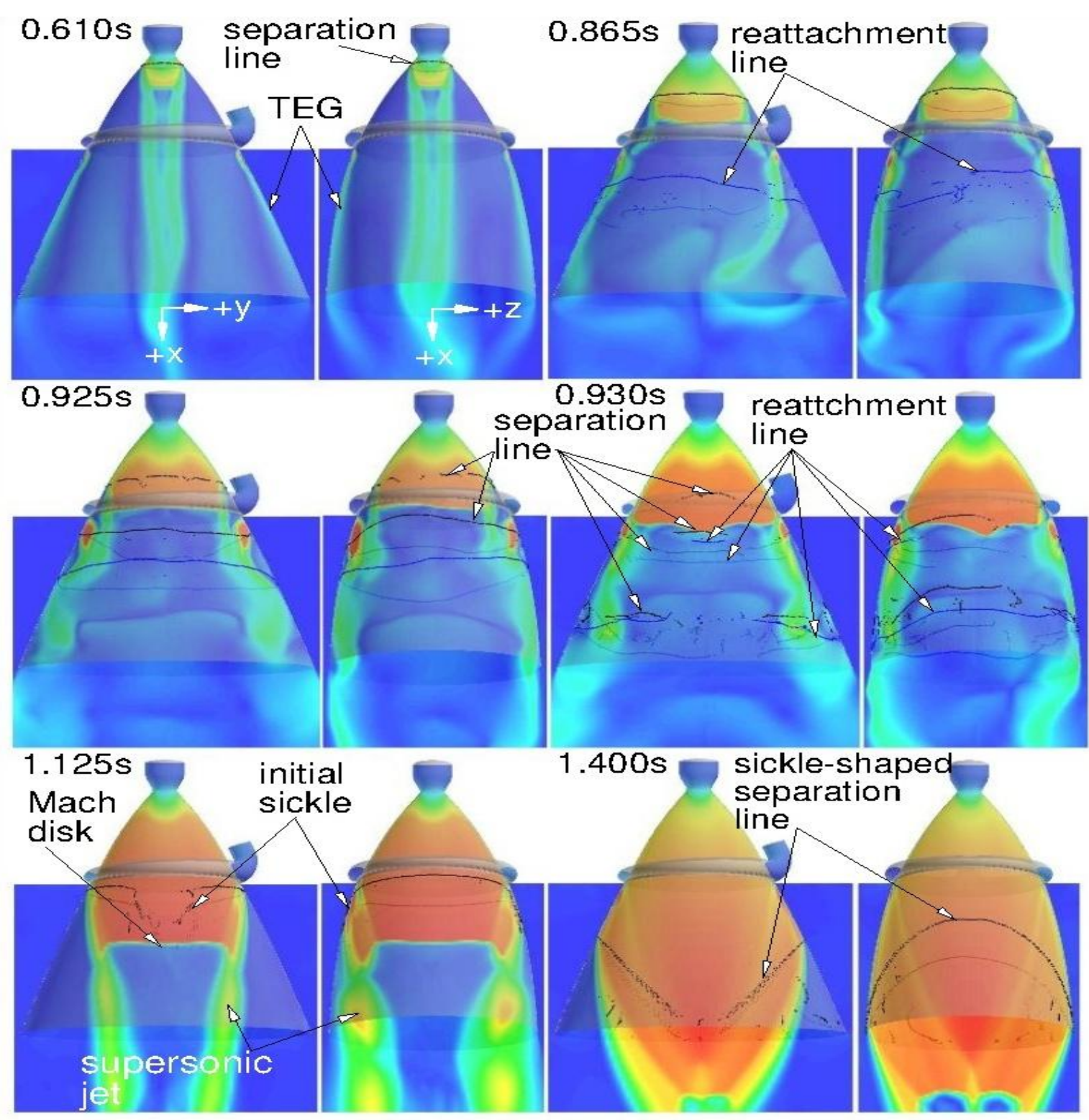




\section{A Comparison of the Computed Local Peak Side Loads}

\begin{tabular}{|c|c|c|c|c|}
\hline \multirow[t]{2}{*}{ Case } & \multicolumn{4}{|c|}{ Peak side loads, $\mathrm{kN}$} \\
\hline & Description & Long axis & This study & Previous study \\
\hline Nominal & perfectly round & - & $2114[19]$ & 2114 [19] \\
\hline 1 & slightly ovallized & $\mathrm{Z}$ & $3309(+57 \%)$ & $2668(+26 \%)[19]$ \\
\hline 2 & slightly ovalized & $\mathrm{y}$ & $3376(+60 \%)$ & - \\
\hline 3 & more ovalized & $\mathrm{z}$ & $3175(+50 \%)$ & $3275(+55 \%)[19]$ \\
\hline 4 & more ovalized & $\mathrm{y}$ & $3268(+55 \%)$ & - \\
\hline 5 & $\begin{array}{l}\text { significantly } \\
\text { ovalized }\end{array}$ & $\mathrm{z}$ & $2715(+28 \%)$ & $2171(+2.7 \%)[19]$ \\
\hline 6 & $\begin{array}{c}\text { significantly } \\
\text { ovalized }\end{array}$ & $\mathrm{y}$ & $1738(-18 \%)$ & - \\
\hline
\end{tabular}




\section{Conclusions}

- Six out-of-round nozzle extension cases were computed with three different degrees of ovalization on y and $z$ axes: a slightly ovalized, a more ovalized, and a significantly ovalized.

- Separation line jump is the critical side load physics

- Comparing to the peak side load of the perfectly round thruster, those of the slightly ovalized cases increased by $57 \%$ and $60 \%$, those of more ovalized cases increased by $50 \%$ and $55 \%$, and those of the significanly ovalized cases increased by $28 \%$ and $-18 \%$ for the elongation along the $z$ and $y$ axes, respectively.

- For the significantly ovalized cases, the difference between the peak side loads comes from the location of the single TEG inlet duct.

- A general theory on the impact of geometry deformation on the transient peak side loads is developed:

- Under the assumptions of this effort, the flow instability overtakes the flow directionality in the slight ovalized cases, while sign of flow directionality developed after thruster flowing full in the more ovalized cases, and the flow directionality overcomes flow instability in the significantly ovalized cases. 